\title{
Digital dissection of the pelvis and hindlimb of the red-legged running frog, Phlyctimantis maculatus, using Diffusible lodine Contrast Enhanced computed microtomography (DICE $\mu \mathrm{CT}$ )
}

\author{
Amber J Collings ${ }^{\text {Corresp., } 1,2}$, Christopher T Richards ${ }^{2}$ \\ ${ }^{1}$ School of Science Engineering and Design, Teesside University, Middlesbrough, United Kingdom \\ 2 Structure and Motion Laboratory, Royal Veterinary College, London, United Kingdom \\ Corresponding Author: Amber J Collings \\ Email address: A.Collings@tees.ac.uk
}

Background. The current study applies both traditional and Diffusible lodine Contrast Enhanced computed microtomography (DICE $\mu \mathrm{CT}$ ) techniques to reveal the musculoskeletal anatomy of Phlyctimantis maculatus. DICE $\mu$ CT has emerged as a powerful tool to visualise intricate musculoskeletal anatomy. By generating 3D digital models, anatomical analyses can be conducted non-destructively, preserving the in situ 3D topography of the system, therefore eliminating some of the drawbacks associated with traditional methods. We aim to describe the musculature of the spine, pelvis, and hindlimb, compare the musculoskeletal anatomy and pelvic morphology of $P$. maculatus with functionally diverse frogs, and produce 3D digital anatomy reference data.

Method. An adult frog was stained using an aqueous Lugol's solution and scanned in a SkyScan1176 in vivo $\mu$ CT scanner. Scan images were reconstructed, resampled, and digitally segmented to produce a 3D model. A further adult female frog was dissected traditionally for visualisation of tendinous insertions.

Results. Our work revealed three main findings: 1) P. maculatus has similar gross muscular anatomy to Rana catesbeiana (bullfrog) but is distinct from those species that exhibit ancestral traits (leopelmids) and those that are highly specialised (pipids), 2) P. maculatus's pelvic anatomy best fits the description of Emerson's walking/hopping pelvic morphotype IIA, and 3) a split in the semimembranosus and gracilis major muscles is consistent with the reported myology in other anuran species.

Discussion. While DICE $\mu \mathrm{CT}$ methods were instrumental in characterising the 3D anatomy, traditional dissection was still required to visualise important structures such as the knee aponeurosis, tendinous insertions, and fasciae. Nonetheless, the anatomical data presented here marks the first detailed digital description of an arboreal and terrestrial frog. Further, our digital model presents $P$. maculatus as a good frog model system and as such has formed a crucial platform for further functional analysis within the anuran pelvis and hindlimb. 
1 Digital dissection of the pelvic and hindlimb of the

2 red-legged running frog, Phlyctimantis maculatus,

3 using Diffusible lodine Contrast Enhanced computed

4 microtomography (DICE $\mu \mathrm{CT}$ )

${ }^{1}$ School of Science Engineering and Design, Teesside University, Middlesbrough, UK

${ }^{2}$ Structure and Motion Laboratory, Royal Veterinary College, Hatfield, UK 10

*Corresponding Author:

\section{Abstract}

Background. The current study applies both traditional and Diffusible Iodine Contrast Enhanced computed microtomography (DICE $\mu \mathrm{CT}$ ) techniques to reveal the musculoskeletal anatomy of Phlyctimantis maculatus. DICE $\mu \mathrm{CT}$ has emerged as a powerful tool to visualise intricate musculoskeletal anatomy. By generating 3D digital models, anatomical analyses can be conducted non-destructively, preserving the in situ 3D topography of the system, therefore eliminating some of the drawbacks associated with traditional methods. We aim to describe the musculature of the spine, pelvis, and hindlimb, compare the musculoskeletal anatomy and pelvic morphology of $P$. maculatus with functionally diverse frogs, and produce 3D digital anatomy reference data.

Method. An adult frog was stained using an aqueous Lugol's solution and scanned in a SkyScan1176 in vivo $\mu \mathrm{CT}$ scanner. Scan images were reconstructed, resampled, and digitally segmented to produce a 3D model. A further adult female frog was dissected traditionally for visualisation of tendinous insertions.

Results. Our work revealed three main findings: 1) P. maculatus has similar gross muscular anatomy to Rana catesbeiana (bullfrog) but is distinct from those species that exhibit ancestral traits (leopelmids) and those that are highly specialised (pipids), 2) P. maculatus's pelvic anatomy best fits the description of Emerson's walking/hopping pelvic morphotype IIA, and 3) a split in the semimembranosus and gracilis major muscles is consistent with the reported myology in other anuran species.

Discussion. While DICE $\mu \mathrm{CT}$ methods were instrumental in characterising the $3 \mathrm{D}$ anatomy, traditional dissection was still required to visualise important structures such as the knee aponeurosis, tendinous insertions, and fasciae. Nonetheless, the anatomical data presented here marks the first detailed digital description of an arboreal and terrestrial frog. Further, our digital 
39

40

41

42

43

44

45

46

47

48

49

50

51

52

53

54

55

56

57

58

59

60

61

62

63

64

65

66

67

68

69

70

71

72

73

74

75

76

77

78

model presents $P$. maculatus as a good frog model system and as such has formed a crucial platform for further functional analysis within the anuran pelvis and hindlimb.

\section{Introduction}

Anurans are key to understanding the intricate connections among vertebrate musculoskeletal elements enabling limb motion (Lombard \& Abbott, 1907; Kargo \& Rome, 2002; Kargo et al. 2002). As such, frogs have been used as models for understanding the biomechanics of jumping (e.g. Calow \& Alexander, 1973; Kargo et al., 2002; Roberts \& Marsh, 2003; Astley \& Roberts, 2014; Porro et al., 2017), swimming (Gillis \& Biewener, 2000; Nauwelaerts \& Aerts, 2002; Richards \& Biewener, 2007; Clemente \& Richards, 2013) and walking (Ahn et al., 2004; Reynaga et al., 2018). One particular region of interest in anurans is the morphological variation in the sacrum and pelvis, thought to play a large role in the locomotor versatility observed across anuran taxa (Emerson, 1979). Three distinct morphotypes were defined by Emerson, Type I, Type IIA, and Type IIB, differing in muscle origin, insertion, and size, shape of sacral diapophysis, and the nature of the ligamentous attachments. Hypothesised to allow for differential rotations about the ilio-sacral joint, the different morphotypes are understood as specialisations for different locomotor behaviours, such as swimming (Type I), walking (Type IIA), and jumping (Type IIB) (Emerson, 1979; Reilly and Jorgensen, 2011; Jorgensen and Reilly, 2013).

In this study we explore the pelvic and hindlimb anatomy of the hyperoliid Phlyctimantis maculatus (Portik \& Blackburn, 2017) (previously known as Kassina maculata). While colloquially called the red-legged running frog, $P$. maculatus excels at walking, running, hopping, climbing, and jumping (Ahn et al., 2004; Porro et al., 2017; Richards et al., 2017; 2018). With muscular hindlimbs, this species forages in the savannah, long grass, and bushland terrestrially (Bwong et al., 2017) while also escaping into the trees, climbing and jumping arboreally, making use of their well-developed toepads (Loveridge, 1976). Given their proclivity to walking, running, and climbing, we predict this species possesses a Type IIA pelvic morphotype. This 'walking morphotype' is described as having a dorsoventrally flattened sacrum with slight expansion of the diapophyses and triangular ilio-sacral ligaments (Emerson, 1979).

Additional to using multiple locomotor modes, $P$. maculatus are easy to work with, robust to maintain in laboratory conditions, and can currently be sourced ethically in the USA/EU/UK. We will use both traditional and emerging 3D techniques to study the musculoskeletal anatomy of this 'multifunctional' frog in detail. Using aqueous iodine to increase the radiopacity of the soft tissues, diffusible iodine contrast enhanced computed microtomography (DICE $\mu \mathrm{CT}$ ) allows anatomical analyses to be conducted non-destructively (Metscher, 2009a; 2009b; Herdina et al., 2010; Vickerton et al., 2013; Gignac \& Kley, 2014; Lautenschlager et al., 2014; Herdina et al., 2015; Porro \& Richards, 2017; See Gignac et al., 2016 for a full review) and has emerged as a powerful functional morphology tool to visualise intricate musculoskeletal anatomy across 
79 diverse systems (For example: Cox \& Jeffery, 2011; Jeffery et al., 2011; Baverstock et al., 2013;

80 Düring et al., 2013; Cox \& Faulkes, 2014; Lautenschlager et al., 2014; Holliday et al., 2013;

81 Gignac \& Kley, 2014; Kleinteich \& Gorb, 2015; Klinkhamer et al., 2017, Bribiesca-Contreras \&

82 Sellers, 2017, See Gignac et al., 2016 for a comprehensive review).

83

84 Our current work builds upon the first, and only, published DICE $\mu$ CT description of a frog to

85 date, performed on Xenopus laevis (Porro \& Richards, 2017). While Xenopus is regularly used as

86 a model species, they are fully aquatic and specialised swimmers. We therefore present the first

87 detailed digital dissection of a 'multifunctional' terrestrial and arboreal species. By combining

88 virtual techniques with traditional dissection we aim to: 1) describe the locomotor and postural

89 musculature of the spine, pelvis, and hindlimb, 2) contextualise and compare the pelvic

90 morphotype and musculoskeletal anatomy of $P$. maculatus with other functionally diverse frogs,

91 and 3) contribute to the growing collection of 3D digital anatomy data for further use in research

92 and education (See Supplemental Data S1).

93

94 Materials \& Methods

95 Musculoskeletal geometry

96 Diffusible iodine contrast enhanced $\mu C T$ scanning

97 One adult $P$. maculatus frog (15.7 g body mass), obtained from Amey Zoo (Hempstead, UK),

98 was euthanised by Tricaine methanesulfonate (MS222) overdose (0.02\% MS222, 0.04\%

$99 \mathrm{NaHCO}_{3}$ ) followed by removal of the heart (compliant with primary and secondary methods of

100 amphibian euthanasia as per procedures approved by Home Office License 70/8242). The

101 wound in the chest was closed using non-absorbable braided silk suture (6-0) to limit internal

102 exposure to fixative and staining solution therefore avoiding over-staining. The frog (whole and

103 un-skinned) was fixed in 10\% neutral buffered formalin (NBF) (HT501128, Sigma Aldrich) for

10429 hours, at room temperature, in a darkened environment. Following the fixation process, any

105 remaining fixative was removed by transferring the specimen in to a PBS solution where it was

106 left soaking overnight, at room temperature. To enhance soft tissue contrast for imaging,

107 predominantly of the muscular anatomy, the frog was stained using an aqueous Lugol's solution

108 (L6146, Sigma Aldrich, a.k.a. iodine potassium iodide, $\mathrm{I}_{2} \mathrm{KI}$ ). To avoid over staining, test scans

109 were performed at regular intervals throughout the staining process. After each test scan the

110 specimen was re-introduced to the stain. Depending on the results of the scan, various

111 recommendations were applied to increase stain perfusion, including skinning the specimen

112 (conducted after 3 days), increasing the stain concentration (conducted after 16.5 days), and

113 injecting stain into body (conducted after 31.5 days) (see Table 1). The frog was placed in $70 \%$

114 pure ethanol (02877, Sigma Aldrich) for preservation during transport to and from the scanner.

115 All $\mu \mathrm{CT}$ scans were conducted on the SkyScan1176 in vivo $\mu \mathrm{CT}$ scanner (Bruker microCT,

116 Belgium) in the Biological Services Unit of the Royal Veterinary College, Camden campus. The

117 specimen was wrapped in cellophane and taped down for each scan to prevent drying out or

118 movement during imaging. For each of the test scans, a section of the mid-thigh and/or pelvis 
119 was chosen for imaging since this was a time efficient way to check image quality of both bone 120 and ample soft tissue. After a total of 39 days, the entire specimen was imaged in the final scan $121(17.64 \mu \mathrm{m}$ resolution, $50 \mathrm{kV}, 362 \mu \mathrm{A}, 1 \mathrm{~mm}$ Al filter). The scan images were then reconstructed 122 using NRecon software (V1.6.10.1, Bruker microCT, Belgium), showing the subcutaneous soft

123 124

125

126

127

128

129

130

131

132

133

134

135

136

137

138

139

140

141

142

143

144

145

146

147

148

149

150

151

152

153

154

155

156

157

158 tissue topography of $P$. maculatus (Figure 1A-C).

\section{Visualisation and segmentation}

The reconstructed DICE $\mu \mathrm{CT}$ scan images from the final scan were resampled ( 1 in 5$)$ and then visualised and digitally segmented in Amira 6.0.1 (FEI, Oregon, USA) (Figure 2A-D). The multiplanar viewer function tab was used to create a volume model of all structures. Both the magic wand and paintbrush tools of the segmentation editor function tab were used to assign voxel selections as either bone or muscle material. Voxel assignment was made on the basis greyscale value, those of the lightest colour denoted bone or muscle, whereas black voxels denoted air space. Due to limitations of the technique (see Discussion), author's discretion and anatomical expertise were required for selection and assignment of voxels at the boundary between two materials. Every individual bone and muscle between the $4^{\text {th }}$ vertebra and the distal digits of the hindlimbs were assigned as a separate material. Muscle and bone identifications were performed with the aid of previously published descriptions of other frog species (Dunlap, 1960; Emerson \& De Jongh, 1980; Přikryl et al., 2009). Once the material selections for all muscles were complete, the segmented label field data was resampled (data resampled by $50 \%$ in the $\mathrm{Z}$ direction) before being rendered into 3D surface meshes to produce a 3D representation of the musculoskeletal anatomy of the frog lower spine, pelvis, and hindlimb (Figure 2D). During surface rendering the file underwent constrained smoothing to minimise the visual appearance of the voxels, providing a more even surface and therefore realistic representation of the tissues. Each material surface mesh was exported individually as an STL file. Using the software 3Matic (Materialise Inc., Leuven, Belgium), the individually exported meshes corresponding to the bones of the spine, pelvis, hindlimb, and foot, as well as the individual muscles of the left side (spanning from the spine to the tarsometatarsal [TMT] joint) were combined to create a 3D model of $P$. maculatus (Figure 2D). Additionally, viewable as a 3D PDF, the digital model presents all skeletal material and all muscles of the left side, totalling 17 bones and 41 muscles (Supplemental Data S1, see Supplemental Article S1 for 3D PDF user guide). The individual metatarsals and phalangeal foot bones are grouped together and referred to as the metatarsals and digits, respectively.

\section{Traditional dissection}

Due to the limitations of DICE $\mu \mathrm{CT}$ to visualise tendinous material (see Discussion), musculoskeletal anatomy data were additionally obtained from a female adult frog by traditional means (specimen P. maculatus, body mass: 31.20 g, Source: Amey Zoo, Hempstead, UK). This animal had been previously euthanised using the methods described above, and fixed in 10\% NBF (HT501128, Sigma Aldrich) for 24 hours. Each muscle of the spine, pelvis, and hindlimb 
159

160

161

162

163

164

165

166

167

168

169

170

171

172

173

174

175

176

177

178

179

180

181

182

183

184

185

186

187

188

189

190

191

192

193

194

195

196

197

198

(left side only) was identified, described, and removed in its entirety. Identifications were made with the aid of both the digital dissection of the 3D model (current work) as well as the previously published dissection data (Ecker 1889, Dunlap, 1960; Emerson \& De Jongh, 1980; Duellman \& Trueb, 1986; Přikryl et al., 2009). The muscle names used throughout the current study are consistent with previous anuran dissection literature (Dunlap, 1960; Emerson, 1979; 1982; Emerson \& De Jongh, 1980; Duellman \& Trueb, 1986; Přikryl et al., 2009).

\section{Results}

Musculoskeletal geometry

Using traditional and digital dissection, 41 muscles were identified between the back and the proximal foot. We have grouped muscles as per their anatomical region i.e. the back and pelvis, thigh, shank, tarsals and foot. A summary of the detailed gross anatomy findings, including origins, insertions, and notable features are presented in Table 2. Figures 3-6 present a superficial, medial, deep, and skeletal digital dissection.

Six muscles were identified belonging to the back and pelvic muscles group: the LD, IL, CS, CI, IE, and PY. A fascial sheet, found directly beneath the skin of the dorsal side, covered the entire back, beneath which led the two axial muscles IL and LD, and the two pelvic muscles CI and CS (Figure 3C; Figure 4C; Figure 7A-B). The IE muscle led along the lateral surface of the iliac shaft (Figure 3 B-C; Figure 4B; Figure 7B) whereas the PY muscle was observed joining the urostyle tip to the femur (Figure 3C; Figure 4C).

In total, seventeen muscles made up the muscle mass of the thigh: II, TFL, GL, CR, GR, SM, IFB, IFM, SA, AL, ST, PEC, OE, AM, QF, OI, and GE. Superficially, the dorsal muscle mass of the thigh included the GL and CR (Figure 3C; Figure 7C). The TFL was also visible and positioned proximal to the CR (Figure 3B). Together, SM and GR made up the majority of the muscle mass of the ventral thigh (Figure 3A and C; Figure 7C-D). Both a minor and a major belly of the GR were observed, the minor appearing only as a thin slip of muscle running along the lateral side of its major counterpart (Figure 7D). The IFB was positioned between and slightly deep to the GL and SM along the lateral surface of the thigh, while the SA and AM muscles were positioned on the medial surface between the GR and CR (Figure 3, Figure 4; Figure 8A-D). Deeper dissection revealed the II muscle which crossed the hip joint by wrapping around the ventral surface of the ilium (Figure 4B-C; Figure 5B-C). The AL led medial to II and directly beneath SA (Figure 4B). The ST was split into two heads that ran along the ventral surface of the femur (Figure 4A and C; Figure 8A-B). The small muscles of the hip joint were deeper still. The IFM muscle was positioned lateral and ventral to II, whereas PEC and QF were positioned medial and ventral to II (Figure 5). Deep to OE, the OI muscle covered the whole lateral portion of the pelvic rim, cupping the hip joint (Figure 5A). The QF and GE muscles interacted closely with each other, forming a fleshy connection between the posterior rim of the pelvis and the proximal femur (Figure 5A and $\mathrm{C}$ ). 
199

200

201

202

203

204

205

206

207

208

209

210

211

212

213

214

215

216

217

218

219

220

221

222

223

224

225

226

227

228

229

230

231

232

233

234

235

236

237

238

The six muscles of the shank included the PL, TiP, TiAL, PER, ECB, and TiAB. The PL muscle made up the vast majority of the posterior tibiofibular muscle mass (Figure $3 \mathrm{~A}$ and $\mathrm{C}$; Figure $8 \mathrm{~F}$ ). Superficially, the PER muscle ran along the lateral border of the tibiofibula (Figure 3C; Figure 7C; Figure 8G), whereas the TiAL muscle, which split into two distinct heads, appeared along the anterior surface of the shank (Figure 3B; Figure 4B-C; Figure 8F). Deeper dissection revealed the TiP, ECB, and the TiAB. The TiP was positioned deep to PL and covered the distal two thirds of the posterior surface of the tibiofibula. Medial to TiP was the ECB, wrapping medially from the proximal anterior surface to cover the medial surface of the tibiofibula (Figure 3A; Figure 4A-B; Figure 8F). Finally, TiAB was positioned deep to ECB and the two heads of TiAL (Figure 4B; Figure 5A-C).

Twelve muscles were identified belonging to the tarsals and proximal foot, including: PP, TaP, TaA, EDCL, ABD and ABP, FDBS, AP, TPP and D, EBS, and IN. Superficially, the TaA, EDCL, and ABD and $P$ made up the anterior muscle mass of the tarsals, while the posterior muscle mass consisted of the FDBS and PP muscles (Figure 3A and C; Figure 4C; Figure 5A and $\mathrm{C}$ ). While $\mathrm{ABD}$ and $\mathrm{ABP}$ were merged in the digital dissection of P. maculatus (Figure 3BC) the fragility of these muscles during traditional dissection made it challenging to discern whether or not these muscles were indeed separate or not. The TaP muscle covered the medial portion of the astralagus, superficially (Figure 3A; Figure $8 \mathrm{H}$ ), whereas laterally, the calcaneum was covered by ADB and P (Figure 3B-C). Distal to the TaP, the AP muscle crossed the TMT joint (Figure 3A; Figure 4A; Figure 8H). Deep muscles of this region of the hindlimb included the EBS, TPP and D, and IN. We have referred to EBS as a single unit however as can be visualised in Figure 4B-C and Figure 8I, while there is a common origin, this muscle separates distally into multiple separate heads. The TPP and D muscles cover the posterior surface of the TMT joint (Figure 3A; Figure 4A; Figure 5A-B and B), whereas the IN spans the interosseous gap between the two elongate tarsal bones (Figure 4B; Figure 5B).

Notably, connective tissue septa were observed in the two axial muscles, LD and IL, as well as in two muscles of the thigh, SM and GR. While both the LD and IL consisted of multiple segments unified by thin septa to form elongate muscle masses (Figure 9A-B), in SM and GR, the connective tissue septum split the muscle bellies approximately in half, separating the proximal and distal ends (Figure 9C-F). In the SM muscle the separation was a diagonal line from left to right at a slight proximal-distal angle (Figure 9C and D), whereas in the GR the separation was a ' $U$ ' shaped line running through the middle of the muscle belly from left to right (Figure 9E and F). In the digital scan reconstruction images the separations in GR and SM were visible as thin radiolucent darker lines transecting the middle of the muscle bellies (Figure 9D and F). As in the axial muscles, the separations in these muscles appeared to interrupt the parallel muscle fibres.

\section{Pelvic morphotype verification}

PeerJ reviewing PDF | (2018:12:33246:2:0:NEW 16 Apr 2019) 
239 Comparison of the traditional and digital dissection findings with descriptions of Emerson's

240 three morphotypes revealed that $P$. maculatus's pelvis best fits the description of morphotype

241 IIA (Figure 10). The sacrum was dorsoventrally flattened with some lateral diapophyseal

242 expansion, and ligaments appeared triangular in shape. Additionally, the sacro-iliac joint of $P$.

243 maculatus allowed the ilia to slide anterioposterially, rotate laterally, and rotate dorsoventrally,

244 whereas the sacro-urostylic joint was bicondylar and relatively inflexible (tested via manual

245 manipulation).

246

247

248

\section{Discussion}

In this paper, we have described and characterised the musculoskeletal anatomy of P. maculatus

249 for the first time. Paired with traditional dissection, the recently developed DICE $\mu \mathrm{CT}$ technique

250 was used to produce a detailed account of the complex 3D geometry of the distal spine, pelvis,

251

252

253

254

255

256

257

258

259

260

261

262

263

264

265

266

267

268

269

270

271

272

273

274

275

276

277

278

and hindlimb. The work is currently the first digital anatomical description of a terrestrial/arboreal species of frog and represents only the second time DICE $\mu \mathrm{CT}$ has been used in the visualisation and description of anuran musculoskeletal anatomy. The digital dissection conducted here allowed accurate visualisation of muscular anatomy of this species as never seen before. Furthermore, the 3D PDF (available in SI1, see SI2 for user guide), allows readers to perform a non-destructive and repeatable digital dissection of this species for themselves.

\section{Musculoskeletal geometry}

The use of DICE $\mu C T$ scans, $3 D P D F$, and digital dissection

Dissections revealed intricate musculoskeletal anatomy within the hindlimb and pelvic apparatus, consisting of a large number of muscles, and multiple instances of convoluted curved muscle pathways, where muscles wrapped around bony and soft tissue structures or passed through other muscles. Using DICE $\mu \mathrm{CT}$ enabled us to capture and preserve the $3 \mathrm{D}$ topography of the musculoskeletal system of this species in a level of detail that is challenging to achieve using traditional methods. DICE $\mu \mathrm{CT}$ has many other advantages over traditional dissection, including its non-destructive nature, opening this technique up to the anatomical investigation of specimens that cannot undergo destructive sampling. Moreover, iodine staining has been suggested to be reversible (Bock \& Shear, 1972 cited in Jeffery et al., 2011), allowing repeated scanning of the same sample with optimised stain concentrations for different features (Jeffrey et al., 2011).

\section{Comparative musculoskeletal anatomy}

Comparing our dissection findings from $P$. maculatus, with those of other anuran species (Dunlap, 1960; Přikryl et al., 2009), we found the different anatomical regions exhibited different levels of variation among species. The most variable regions were the spine and pelvis, and the tarsals and proximal foot. Whereas there were fewer examples of anatomical variation in the thigh, and the shank appeared uniform across species. 
279 The anatomical variation of the muscles of the back and the pelvis included variation in insertion 280 sites, some muscle belly shapes, and muscle presence/absence/fusion. While the LD in $P$. 281 maculatus inserted approximately half way down the urostyle, its insertion site in other species 282 ranges from the anterior portion, as in Pelophylax kl. esculentus, to the very tip of the urostyle, as

283

284

285

286

287

288

289

290

291

292

293

294

295

296

297

298

299

300

301

302

303

304

305

306

307

308

309

310

311

312

313

314

315

316

317 in Ascaphus truei (Dunlap, 1960). The IL insertion in P. maculatus is also more proximal than observed in species such as Kaloula pulchra where it extends down onto the iliac shaft (Dunlap, 1960; Prrikryl et al., 2009). While the CS was present as a separate muscle in P. maculatus, in $X$. laevis and Barbourula busuagensis the CS and LD are fused into one muscle belly (Dunlap, 1960; Prikryl et al., 2009). Compared with P. maculatus, which has a clear PY muscle, the PY of X. laevis is reduced and further, is altogether absent in Pipa pipa (Dunlap, 1960; Přikryl et al., 2009; Porro \& Richards, 2017). In contrast, A. truei and Leiopelma hochstetteri possess a caudopuboischiotibialis (the ancestral trait) not present in any of the other species studied by Dunlap (1960) or indeed P. maculatus. Finally, the IE muscle of P. maculatus was narrow and cylindrical, similar to Rhaebo guttatus. In other species the IE appears broader and more fanshaped (Prrikryl et al., 2009), whereas A. truei and L. hochstetteri it is fused with the II muscle (Dunlap, 1960).

The majority of the muscles of the thigh appear uniform among species, however variation is observed in the presence/absence of the AL, number of heads present in the CR and ST, and fusion of some muscle bellies. While P. maculatus shares the presence of AL with Discoglossus pictus, B. busuagensis and Pelobates fuscus, the AL is absent in, Bombina orientalis, $B$. bombina, B. pachypus, Alytes obstetricans, Spea hammondii, Megophrys montana, X. laevis, $P$. pipa, Rhinophrynus dorsalis, Atelopus cruciger, Polypedates leucomystax, and Chiromantis xerampelina (Dunlap, 1960; Přikryl et al., 2009). Furthermore, while in P. maculatus, and most other species, $\mathrm{CR}$ is one muscle belly, in specialised aquatic species, the CR muscle is divided into two incomplete heads (Dunlap, 1960). Finally, A. truei and L. hochstetteri exhibit fusing and combinations of multiple thigh muscles (SA and ST; AL and PEC; QF and GE) that were not observed in P. maculatus (Dunlap, 1960).

While muscles of the shank were not variable, multiple differences in muscle proportions, attachment sites, presence/absence and splitting/fusion are evident in the tarsals and proximal foot. Like most other species, P. maculatus had two distinct heads of the TiAL muscle, which were of roughly equal size. Dunlap (1960) reported variation in the proportions of the two heads, and the position at which the muscle bellies of TiAL diverge. The TaP muscle of $P$. maculatus is similar to that of other Ranids but is smaller than seen in A. truei and L. hochstetteri (Dunlap, 1960). The EBS muscle splits into multiple heads in all species however the digit upon which the middle head of this muscle inserts is variable among species (Dunlap, 1960). As in the other areas of the hindlimb, the highly specialised aquatic species, such as P. pipa and X. laevis, lacked muscles which were present in P. maculatus, such as the EBS, AP, and TPP and D. Additionally, 
318 while in $P$. maculatus, the PP remains separate from FDBS, in A. truei and L. hochstetteri these 319 two muscles are fused (Dunlap, 1960).

320

321

322

323

324

325

326

327

328

329

330

331

332

333

334

335

336

337

338

339

340

341

342

343

344

345

346

347

348

349

350

351

352

353

354

355

356

357

Overall, P. maculatus had a similar gross muscular anatomy to $R$. catesbeiana and $R$. guttatas but differed from those species that exhibit ancestral traits (leopelmids) and those that are highly specialised (pipids) (Dunlap, 1960; Přikryl et al., 2009). The highly specialised, P. pipa and X. laevis lacked muscles which were present in P. maculatus, such as the PY (which is only reduced in Xenopus [Porro et al, 2017]), CI, EBS, AP, and AL. Whereas, A. truei and L. hochstetteri exhibit fusing and combinations of multiple muscles (SA and ST; AL and PEC; OE; QF and GE; PP and FDBS; IE and II) that were not observed in P. maculatus (Dunlap, 1960).

\section{Diversity of hindlimb/pelvis muscle morphology in relation to diversity in function}

In the pelvic region, there is strong evidence linking variation frog musculoskeletal anatomy to diversity in locomotor style (Emerson \& De Jongh, 1980). The region differentiates after metamorphosis and thus the variation seen in this musculature seems to relate to expansion of locomotor capacity as froglets develop (Fabrezi et al. 2014). Indeed, differences in the LD, CI, CS, and IL muscles contribute to functional differences in lateral bending and gliding of pelvis associated with walking and swimming, respectively (Emerson \& De Jongh, 1980). The II, IE, and TFL are derived muscles also likely to influence locomotor mode (Přikryl et al., 2009). For example, IE length correlates with jumping (Fabrezi et al. 2014), thus may be expected to have a similar morphology among jumpers. However, IE morphology of $P$. maculatus differs from other jumpers (e.g. Ranids) owing to its cylindrical shape (see above). Given that the IE may play an important role in bringing the leg upwards and forwards (Kargo \& Rome, 2002), perhaps its shape represents a modification to assist with the swing phase of walking/running.

Compared to the pelvis, evidence for interspecific muscle structure-function relationships in the hindlimb is relatively sparse. As stated above, the thigh region appears more conserved compared to the pelvis and distal hindlimb among species, including P. maculatus. Despite conservation of thigh muscular traits among modern taxa, A. truei and L. hochstetteri (representing "primitive" taxa) exhibit fused musculature (see above). In absence of further modelling analysis (e.g. Kargo \& Rome, 2002), we can only speculate on the functional consequence of fused muscles. Perhaps separate versus fused muscles allows for a greater variation in muscle moment arms, thus increasing the functional workspace of the limb hence enhancing the limb's ability to perform multiple tasks.

Apart from the above discussion based on a small number of species and focused anatomical regions, we are far from a clear and complete understanding of how interspecific variation in muscle morphology relates to locomotor function. In light of broad patterns relating limb, body, and skeletal morphology to locomotor style (Zug, 1978; Emerson, 1988) as well as performance, ecology, and phylogeny (Moen et al., 2013), we also expect relationships to emerge with

Peer) reviewing PDF | (2018:12:33246:2:0:NEW 16 Apr 2019) 
358

359

360

361

362

363

364

365

366

367

368

369

370

371

372

373

374

375

376

377

378

379

380

381

382

383

384

385

386

387

388

389

390

391

392

393

394

395

396

397

muscular morphology. Although certain features of the musculoskeletal system seem to vary independently of ecology/function (Fratani, 2018), we expect that other traits may exhibit morphologically small differences amounting to profound effects on locomotion. In particular, small changes in muscle moment arm distances have a strong impact on muscle function (Lombard \& Abbott, 1907; Kargo \& Rome, 2002). For example, there is great diversity in subtle aspects of bone shape (e.g. ridges on ilia; Reilly \& Jorgensen, 2011) which may alter muscle origins/insertions significantly enough to change muscle moment arms. Moreover, muscles are not mechanically independent; the function of a single muscle depends on the current configuration of the joints, thus is dependent on the action of other muscles (Lombard \& Abbott, 1907; Kuo, 2001; Kargo \& Rome, 2002). Consequently, analyses that treat all muscles independently might overlook synergistic effects of small changes in one muscle with respect to other muscles. Regardless, the species currently sampled for detailed muscle analysis are likely too few to disentangle function/ecology from phylogenetic effects. Fortunately, recent workers have assembled a vast archive of frog digital anatomy (open Vertebrate; "oVert") and are currently making it available for exploration and study (Watkins-Colwell et al., 2018). Thus, future work can build upon our observations as well as past work to accumulate sufficient intraspecific data to apply rigorous comparative/phylogenetic methods (e.g. Moen et al., 2013; Fratani, 2018) towards elucidating muscle morphology-function relationships across Anura.

\section{Gracilis major and Semimembranosus myology}

The split found in the SM and GR (major) is unique among the dozens of muscles of the leg and pelvis. Although this tendinous "septation" is well-characterised in all other anurans observed (Dunlap 1960; Duellman and Trueb, 1986; Přikryl et al., 2009), neither the developmental mechanism nor the biomechanical significance of this muscle structure is known. One possible explanation is incomplete fusion of two evolutionary/developmentally distinct muscles which appears as intramuscular separation. However, Přikryl et al. (2009) note that the hindlimb extensor muscles in modern frogs have not changed over the course of evolution; thus, we speculate that separation may not be a developmental/evolutionary artefact, but rather may have functional significance. For example, tendinous separations between muscle bellies are not unique to anurans; separated muscles have been described in salamanders (Ashley-Ross, 1992; Walthall \& Ashley-Ross, 2006) and cats (Bodine et al., 1982). In those cases, the divided muscle bellies receive separate innervation (Francis, 1934; Bodine et al., 1982) suggesting that two regions of a single muscle could act independently. If the partitions of the SM and GR were found to have separate innervation, we propose a potential mechanical function as follows. Both the SM and GR muscles span from the pelvis to the knee and insert into the aponeurosis covering the knee. The semimembranosus in particular has been recorded to function both as a femur retractor and a knee flexor and, while it does not act on the knee joint, GR is also dual functional, acting to either retract or adduct the femur (Přikryl et al., 2009). We speculate a separation could act to partition the portions of muscle designated for each role, allowing the animals to fine tune hindlimb motion. Further anatomical investigation determining innervation and/or spatial 
398

399

400

401

402

403

404

405

406

407

408

409

410

411

412

413

414

415

416

417

418

419

420

421

422

423

424

425

426

427

428

429

430

431

432

433

434

435

436

437

partitioning of fibre types would be required to better characterise these muscles. Subsequently, modelling analyses could be performed to assess the biomechanical impact of intramuscular separation.

\section{Phlyctimantis maculatus pelvic morphotype}

Given recent findings that $P$. maculatus are walkers/runners as well as hoppers, jumpers, and climbers (Porro et al., 2017), we evaluated whether the pelvic morpohotype represented walker or jumper traits. Pelvic dissection revealed that $P$. maculatus's anatomy was consistent with the Type IIA morphotype defined by Emerson (1979). The sacrum was dorsoventrally flattened as opposed to the cylindrical sacral shape of Type IIB jumping species, yet lacked the extreme laterally flared diapophyseal expansion and broad ligamentous cuff of the Type I pelvis, as seen in aquatic, swimming species such as P. pipa (Emerson, 1979; 1982; Přikryl et al., 2009).

However, some of the key features of the Type IIA morphotype were subtler in P. maculatus compared with other walking and hopping, and burrowing species. For example, R. guttatus, B. busuagensis, D. pictus S. hammondii, Rentapia hosii, A. obstetricans, Anaxyrus (Bufo) americanus, A. boreas are walking, hopping, or burrowing species that exhibit broader lateral flaring of the sacral diapophysis and a more obvious bow-tie shape sacrum (Přikryl et al., 2009; Reilly and Jorgensen, 2011). Although dorsoventrally flattened, the sacrum of P. maculatus demonstrated less flaring and more posterior lateral projection of the sacral diapophyses, similar to the skeletal morphology of $A$. truei and A. montanus (Reilly \& Jorgensen, 2011). Perhaps the typical Type IIA morphotype features are less prominent in P. maculatus because of its more arboreal ecology and use of both walking and jumping behaviour (as opposed to hopping).

Furthermore, $P$. maculatus also exhibited slightly dorsally ridged ilia and urostyle. Having prominent ridges along the dorsal surface of the ilia is a trait commonly seen among the sagittalhinge Type IIB morphotypes (Emerson 1979; 1982; Reilly \& Jorgensen, 2011). Nonetheless, Reilly \& Jorgensen (2011) reported the same set of features in other representatives of Hyperoliidae (Kassina senegalensis and Hyperolius lateralis), summarising that the pelvic girdle design of this family comprises an expanded sacrum, iliac ridges, and half urostyle ridge. They also categorised this family as walkers, hoppers, and arboreal jumpers. P. maculatus is therefore consistent with their description of hyperoliid frogs. Furthermore, manual manipulation of the ilio-sacral joint prior to and following muscle dissection suggested a capacity for lateral rotation, some anteroposterior sliding, and sagittal bending. Since lateral rotation of this joint is only freely permitted by the Type IIA morphotype (by definition, Emerson 1979; 1982), we felt justified in classifying the pelvis of $P$. maculatus as such. It should also be noted that while the degree of sacral diapophyseal expansion is a useful trait in distinguishing between the sagittal hinge or lateral bender morphotype, the extent of sacral diapophysis lateral expansion is highly variable among anurans (Jorgensen \& Reilly, 2013). 
438 Given the extent of subtle variation observed in the musculoskeletal anatomy of anurans in 439 general, it seems likely that Emerson's categories represent the archetypical morphotypes within 440 each behavioural group (walking/hopping, jumping, and swimming). Those species that use 441 multiple locomotor behaviours possess a subtle blend of pelvic characteristics. Thus, rather than 442 fitting discrete morphotypes, frogs more likely span a continuum of pelvic morphologies 443 depending on the combination of locomotor behaviour expressed by a given species, as suggested previously (Soliz et al. 2016).

447

448

449

450

451

452

453

454

455

456

457

458

459

460

461

462

463

464

465

466

467

468

469

470

471

472

473

474

475

476 A further limitation associated with the DICE methods used here is the inability to visualise

477

DICE $\mu C T$ has proved an excellent method to present the 3D topography of the musculoskeletal system, allowing the visualisation of complex 3D interactions between muscles and other structures not possible with traditional techniques. However, there are some notable caveats associated with DICE $\mu \mathrm{CT}$ that should be discussed here.

The aim of the DICE $\mu \mathrm{CT}$ technique is for the stain to disperse through the soft tissue, increasing contrast (Figure 2A-C), as such, poor diffusion or too low a stain concentration results in poor contrast enhancement. Here, we skinned the specimen in order to assist with stain perfusion however a lack of published methodologies for amphibian staining means we cannot comment on how effective removal of the skin was for this purpose. On the other hand, poor soft tissue contrast can also result from overstaining. Furthermore, a fine balance needs to be struck in order to avoid distortion of the sample due to extreme tissue shrinkage.

Tissue shrinkage is a commonly reported caveat of DICE $\mu \mathrm{CT}$ (Vickerton et al., 2013; Cox \& Faulkes, 2014; Buytaert et al., 2014; Gignac et al., 2016; Bribiesca-Contreras \& Sellers, 2017). Muscle volume shrinkage due to contrast enhanced staining has been previously reported ranging from 10-56\% (Vickerton et al., 2013; Buytaert et al., 2014; Bribiesca-Contreras \& Sellers, 2017). The extent to which shrinking occurs in stained specimens increases with higher concentrations of $\mathrm{I}_{2} \mathrm{KI}$ and can be reduced by using lower concentrations over a longer duration as was implemented in this study (Vickerton et al., 2013; Gingnac \& Kley, 2014). Contrast enhanced staining is therefore a time consuming process and despite us using low concentrations of Lugol's solution here to avoid it, shrinkage of the muscle tissue was observed in our frog. We do not believe the level of shrinkage in our specimen to be detrimental to the overall results of our anatomical assessment since origins, insertions, and pathways are unlikely to have been affected significantly (Cox \& Faulkes, 2014). While muscle volumes are not the focus here, it should be noted that measuring the specific level of shrinkage is an important consideration in those studies reporting quantitative muscle data (for example, see Bribiesca-Contreras \& Sellers, 2017 for their comparison of dissected vs stained muscle volumes).

tendinous or ligamentous tissues. Important structures such as the knee aponeurosis, muscle

\section{Limitations and caveats of DICE $\mu C T$}


478 tendons, or plantar fasciae were therefore indistinguishable in the scan data and excluded from

479 the 3D PDF. This caveat was also encountered by Porro \& Richards (2017) who suggest using

480 agents that bind to collagen as an alternative. Descamps et al. (2014) demonstrate that

481 phosphotungstic acid (PTA) has a preference for binding to collagen and connective tissues

482 whereas phosphomolybdenic acid (PMA) provides good contrast for the visualisation of cartilage

483 using CT. When using any chemicals health and safety precautions must be adhered to, not all

484 laboratory spaces are suitable to conduct the aforementioned procedures.

485

486

487

Finally, obtaining the highly detailed results of DICE $\mu \mathrm{CT}$ is time consuming, making analysis

488 of several specimens of one species impractical. Consequently, studies such as this assume low intra-species variation. Moreover, the subsequent segmentation of the $\mu \mathrm{CT}$ scan data requires anatomical expertise and relies on the user's discretion to appropriately define voxel material. The final 3D model is therefore best defined as a 3D representation of the anatomy of an example specimen.

492

Despite the limitations, DICE $\mu \mathrm{CT}$ as a technique has already begun to revolutionise the way

494

495

496

497

498

499

500

501

502

503

504

505

506

507

508

509

510

511

512

513

514

515

516

517 anatomy is visualised and studied. With further use in a wider range of taxa, the protocols are likely to improve and become more standardised as a wider knowledge base for troubleshooting is generated. Even though this is one of the earliest uses of the technique in anurans, the results obtained in this study were remarkable and facilitated a deeper understanding of the gross anatomy of $P$. maculatus.

\section{Future work}

Recently, anatomical reconstructions created using DICE $\mu$ CT have been used as the foundation for musculoskeletal models to investigate structure-function relationships of the locomotor musculoskeletal system (Charles et al., 2016a; 2016b; Allen et al., 2017). We propose to use our 3D digital model to generate an anatomically accurate musculoskeletal model of $P$. maculatus, allowing us to explore the mechanical effect of the complex curved muscle trajectories, and test our speculative hypotheses regarding the implications of separate innervation in the same muscle belly (such as seen in the SM and GR). Furthermore, our musculoskeletal model can be applied to questions regarding evolutionary adaptations. For example, by altering muscle attachment sites, and/or skeletal proportions to mimic those of extinct species, we can explore the functional significance of such adaptations.

\section{Conclusions}

Here we present a complete assessment of the musculoskeletal anatomy and 3D geometry of the lower spine, pelvis, and hindlimb of Phlyctimantis maculatus. Traditional and digital dissection revealed that the musculoskeletal anatomy of $P$. maculatus is comparable to other derived species and, as predicted, their pelvic morphology is consistent with the Type IIA morphotype associated with walking and hopping. The DICE $\mu \mathrm{CT}$ technique was a valuable addition to our 
518 methodology, allowing us to visualise muscles interactions in 3D. However, we found this 519 technique still needs to be combined with traditional dissection in order to observe tendinous 520 attachment points. Nonetheless, the anatomical data presented here act as an excellent

521 educational resource and form a crucial platform for further functional analysis within the anuran

522 pelvis and hindlimb. Both the digital and traditional dissections performed are critical for the 523 creation of an anatomically accurate musculoskeletal models that could be used to perform 524 moment arm analyses. Future work will use such models to investigate muscle function during 525 both walking and jumping locomotion in P. maculatus.

526

527

\section{Acknowledgements}

528

We thank Mark Hopkinson for invaluable assistance with the $\mu \mathrm{CT}$ scanning and re-construction.

529 Dr Chris Basu provided valuable comments on draft versions and Dr Zoë Davies contributed

530 interesting discussion of muscle anatomy. Dr James Charles, along with Dr Sandy Kawano,

531 further assisted in the creation of the 3D PDF. Thank you to all reviewers for their thoughtful

532 comments and suggestions.

533

534

\section{References}

535

Ahn, A. N., Furrow, E. and Biewener, A. A. (2004). Walking and running in the red-legged

536 running frog, Kassina maculata. J. Exp. Biol. 207, 399-410

537 Allen, V. R., Kambic, R. E., Gatesy, S. M. and Hutchinson, J. R. (2017), Gearing effects of

538 the patella (knee extensor muscle sesamoid) of the helmeted guineafowl during terrestrial

539 locomotion. J. Zool. doi:10.1111/jzo.12485

540 Ashley-Ross, M. A. (1992). The Comparative Myology of the Thigh and Crus in the Salamanders Ambystoma tigrinum and Dicamptodon tenebrosus. J. Morphol. 211, 147-163 Astley, H. C. and Roberts, T. J. (2014). The mechanics of elastic loading and recoil in anuran jumping. J. Exp. Biol. 217, 4372-4378 Baverstock, H., Jeffery, N.S. and Cobb, S.N. (2013). The morphology of the mouse masticatory musculature. J. Anat. 223, 46-60

546 Bodine, S. C., Roy, R. R., Meadows, D. A., Zernicke, R. F., Sacks, R. D., Fournier, M. and 547 Edgerton, V. R. (1982). Architectural, histochemical, and contractile characteristics of a unique 548 biarticular muscle: the cat semitendinosus. J. Neurophysiol. 48, 192-201

549 Bribiesca Contreras, F., and Sellers, W. I. (2017). 3D visualisation of the internal anatomy of 550 the sparrowhawk (Accipiter nisus) forelimb using contrast-enhanced micro- CT. PeerJ, 3, e3039. 551 Buytaert, J., Goyens, J., De Greef, D., Aerts, P., and Dirckx, J. (2014). Volume shrinkage of

552

553 bone, brain and muscle tissue in sample preparation for micro-CT and light sheet fluorescence microscopy (LSFM). Microsc. Microanal. 20, 1208-1217.

554 Bwong, B. A., Nyamache, J. O., Malonza, P. K., Wasonga, D. V., Ngwava, J. M., Barratt, C. 555 D., Nagel, P. and Loader, S. P. (2017). Amphibian diversity in Shimba Hills National Reserve, 556 Kenya: A comprehensive list of specimens and species. J. East. Afr. Nat. Hist. 106, 19-46 
557 Calow, L. J. and Alexander, R. McN. (1973). A mechanical analysis of a hind leg of a frog 558 (Rana temporaria). J. Zool. 171, 293-321

559 Charles, J. P., Cappellari, O., Spence, A. J., Hutchinson, J. R. and Wells, D. J. (2016a).

560 Musculoskeletal Geometry, Muscle Architecture And Functional Specialisations Of The Mouse

561 Hindlimb. PLoS One. 11, E0147669

562 Charles, J. P., Cappellari, O., Spence, A. J., Wells, D. J. and Hutchinson, J. R. (2016b).

563 Muscle Moment Arms And Sensitivity Analysis Of A Mouse Hindlimb Musculoskeletal Model.

564 J. Anat. 229, 514-535

565 Clemente, C. J. and Richards, C. T. (2013). Built for rowing: frog muscle is tuned to limb

566 morphology to power swimming. J. R. Soc. Interface. 10, 20130236

567 Cox, P. G. and Faulkes, C. G. (2014). Digital dissection of the masticatory muscles of the

568 naked mole-rat, Heterocephalus glaber (Mammalia, Rodentia). PeerJ. 2, e448

569 Cox, P. G. and Jeffery, N. (2011). Reviewing The Morphology Of The Jaw-Closing

570 Musculature In Squirrels, Rats, And Guinea Pigs With Contrast-Enhanced Microct. Anat. Rec.

571 (Hoboken). 294, 915-928

572 Descamps, E., Sochacka, A., Kegel, B. D., Van Loo, D., Van Hoorebeke, L., and Adriaens,

573 D. (2014) Soft tissue discrimination with contrast agents using micro-CT scanning. Belg. J. Zool.

574 144, 20-40

575 Duellman, W. E. and Trueb, L. (1986). Biology of Amphibians. USA: McGraw-Hill, Inc.,

576 Dunlap, D. G. (1960) The comparative myology of the pelvic appendage in the Salientia. $J$.

577 Morphol. 106, 1-76

578 Düring, D. N., Ziegler, A., Thompson, C. K., Ziegler, A., Faber, C., Müller, J., Scharff, C.,

579 and Elemans, C. P. H. (2013) The songbird syrinx morphome: a three-dimensional,

580 high-resolution, interactive morphological map of the zebra finch vocal organ. BMC Biol. 11, 1

581 Emerson, S. B. and De Jongh, H. J. (1980). Muscle activity at the ilio-sacral articulation of

582 frogs. J. Morphol. 166, 129-144Emerson, S. B. (1979). The ilio-sacral articulation in frogs: form

583 and function. Biol. J. Linn. Soc. 11, 153-168

584 Emerson S. B. (1982). Frog postcranial morphology: identification of a functional complex.

585 Copeia. 3, 603-613

586 Emerson, S. B. (1988). Convergence and morphological constraint in frogs: Variation in

587 postcranial morphology. Chicago, USA: Field Museum of Natural History

588 Fabrezi, M., Manzano, A. S., Abdala, V., and Lobo, F. (2014). Anuran Locomotion:

589 Ontogeny and Morphological Variation of a Distinctive Set of Muscles. Evol. Biol. 41, 308-326

590 Francis, (1934). The anatomy of the salamander. Oxford, UK: The Clarendon Press

591 Gignac, P. M. and Kley, N. J. (2014). Iodine-Enhanced Micro-CT Imaging: Methodological

592 Refinements For The Study Of The Soft-Tissue Anatomy Of Post-Embryonic Vertebrates. $J$.

593 Exp. Zool. B Mol. Dev. Evol. 322, 166-176

594 Fratani, J., Ponssa, M. L., and Abdala, V. (2018). Tendinous framework of anurans reveals an

595 all-purpose morphology. Zool. 126, 172-184 
596 Gignac, P. M., Kley, N. J., Clarke, J. A., Colbert, M. W., Morhardt, A. C., Cerio, D., Cost, 597 I. N., Cox, P. G., Daza, J. D., Early, C. M., Echols, M. S., Henkelman, R. M., Herdina, A. 598 N., Holliday, C. M., Li, Z., Mahlow, K., Merchant, S., Müller, J., Orsbon, C. P., Paluh, D. 599 J., Thies, M. L., Tsai, H. P. and Witmer, L. M. (2016). Diffusible Iodine-Based Contrast600 Enhanced Computed Tomography (Dicect): An Emerging Tool For Rapid, Highresolution, 3-D 601 Imaging Of Metazoan Soft Tissues. J. Anat. 228, 889-909

602 Gillis, G. B. and Biewener, A. A. (2000). Hindlimb extensor muscle function during jumping 603 and swimming in the toad (Bufo marinus). J. Exp. Biol. 203, 3547-3563

604 Herdina, A. N., Herzig-Straschil, B., Hilgers, H., Metscher, B. D. and Plenk, H. (2010).

605 Histomorphology of the penis bone (Baculum) in the gray long-eared bat Plecotus austriacus

606 (Chiroptera, Vespertilionidae). Anat. Rec. (Hoboken). 293, 1248-1258

607 Herdina, A. N., Kelly, D. A., Jahelková, H., Lina, P. H., Horáček, I. and Metscher, B. D. 608 (2015). Testing hypotheses of bat baculum function with 3D models derived from microCT. $J$. 609 Anat. 226, 229-235

610 Holliday, C. M., Tsai, H. P., Skiljan, R. J., George, I. D. and Pathan, S. (2013). A 3D 611 interactivemodel and atlas of the jaw musculature of Alligator mississippiensis. PLoS One. 8, 612 e62806.

613 Jeffery, N. S., Stephenson, R. S., Gallagher, J. A., Jarvis, J. C. and Cox, P. G. (2011).

614 Microcomputed Tomography With Iodine Staining Resolves The Arrangement Of Muscle

615 Fibres. J. Biomech. 44, 189-192

616 Jorgensen, M. E. and Reilly, S. M. (2013). Phylogenetic patterns of skeletal morphometrics and 617 pelvic traits in relation to locomotor mode in frogs. J. Evol. Biol. 26, 929-943

618 Kargo, W. J. and Rome, L. C. (2002). Functional Morphology Of Proximal Hindlimb Muscles 619 In The Frog Rana pipiens. J. Exp. Biol. 205, 1987-2004

620 Kargo, W. J., Nelson, F. and Rome, L. C. (2002). Jumping In Frogs: Assessing The Design Of 621 The Skeletal System By Anatomically Realistic Modeling And Forward Dynamic Simulation. $J$.

622 Exp. Biol. 205, 1683-1702

623 Kleinteich, T. and Gorb, S. N. (2015). Frog tongue acts as muscle-powered adhesive tape. R.

624 Soc. Open. Sci. 2, 150333

625 Klinkhamer, A. J., Wilhite, D. R., White, M. A and Wroe, S. (2017). Digital dissection and 626 three-dimensional interactive models of limb musculature in the Australian estuarine crocodile 627 (Crocodylus porosus). PLoS One. 12, 1-25

628 Kuo, A. D. (2001). The action of two-joint muscles: the legacy of WP Lombard. Classical

629 Papers in Movement Science. Human Kinetics, Champaign, IL, 289-316.

630 Lautenschlager, S., Bright, J. A. and Rayfield, E. J. (2014). Digital Dissection - Using

631 Contrast enhanced Computed Tomography Scanning To Elucidate Hard- And Soft-Tissue 632 Anatomy In The Common Buzzard Buteo Buteo. J. Anat. 224, 412-431

633 Lombard, W. P. and Abbott, F. M. (1907) The mechanical effects produced by the contraction 634 of individual muscles of the thigh of the frog. Am. J. Physiol. 20, 1-60 
635 Loveridge, J. (1976). Strategies of water conservation in southern African frogs. Zool. Africana. 636 11, 319-333Metscher, B. D. (2009a). MicroCT For Comparative Morphology: Simple Staining 637 Methods Allow High-Contrast 3d Imaging Of Diverse Non-Mineralized Animal Tissues. Bmc.

638 Physiol. 9, 11

639 Metscher, B. D. (2009b). MicroCT For Developmental Biology: A Versatile Tool For High640 Contrast 3D Imaging At Histological Resolutions. Dev. Dyn. 238, 632-640

641 Moen, D. S., Irschick, D. J., \& Wiens, J. J. (2013). Evolutionary conservatism and

642 convergence both lead to striking similarity in ecology, morphology and performance across 643 continents in frogs. Proc. R. Soc. B: Bio. Sci., 280, 2013-2156.

644 Nauwelaerts, S. and Aerts, P. (2002). Two distinct gait types in swimming frogs. J. Zool. Lond. 645 258, 183-188

646 Porro, L. B. and Richards, C. T. (2017). Digital dissection of the model organism Xenopus 647 laevis using contrast-enhanced computed tomography. J. Anat. 231, 169-191

648 Porro, L. B., Collings, A. J., Eberhard, E. A., Chadwick, K. P. and Richards, C. T. (2017).

649 Inverse dynamic modelling of jumping in the red-legged running frog Kassina maculata. J. Exp.

650 Biol. 220, 1882-1893

651 Portik, D. M., and Blackburn, D. C. (2016). The evolution of reproductive diversity in

652 Afrobatrachia: A phylogenetic comparative analysis of an extensive radiation of African frogs.

653 Evol. 70-9: 2017-2032

654 Přikryl, T., Aerts, P., Havelková, P., Herrel, A. and Roček, Z. (2009). Pelvic and thigh

655 musculature in frogs (Anura) and origin of anuran jumping locomotion. J. Anat. 214, 100-39

656 Reilly, S. and Jorgensen, M. (2011). The evolution of jumping in frogs: morphological

657 evidence for the basal anuran locomotor condition and the radiation of locomotor systems in

658 crown group anurans. J. Morphol. 272, 149-168

659 Reynaga, C. M., Astley, H. C., and Azizi, E. (2018). Morphological and kinematic

660 specializations of walking frogs. J. Exp. Zool. Part A. 329, 87-98

661 Richards, C. T. and Biewener, A. A. (2007). Modulation of in vivo muscle power output

662 during swimming in the African clawed frog (Xenopus laevis). J. Exp. Biol. 210, 3147-3159

663 Richards, C. T., Eberhard, E. A., and Collings, A. J. (2018). The dynamic role of the ilio-

664 sacral joint in jumping frogs. Biol. Lett. 14, 20180367

665 Richards, C. T., Porro, L. B. and Collings, A. J. (2017). Kinematic control of extreme jump

666 angles in the Red Leg Running Frog (Kassina maculata). J. Exp. Biol. 220, 1894-1904

667 Roberts, T. J. and Marsh, R. L. (2003). Probing the limits to muscle-powered accelerations:

668 lessons from jumping bullfrogs. J. Exp. Biol. 206, 2567-2580

669 Soliz, M., Tulli, M. J. and Abdala, V. (2016). Osteological postcranial traits in hylid anurans

670 indicate a morphological continuum between swimming and jumping locomotor modes. $J$.

671 Morph. 278, 403-417

672 Vickerton, P., Jarvis, J. and Jeffery, N. (2013). Concentration-Dependent Specimen Shrinkage

673 In Iodine-Enhanced MicroCT. J. Anat. 223, 185-193 
674 Walthall, J. C. and Ashley-Ross, M. A. (2006). Postcranial myology of the California newt, 675 Taricha torosa. Anat. Rec. Part A. 288, 46-57

676 Watkins-Colwell, G., Love, K., Randall, Z., Boyer, D., Winchester, J., Stanley, E., \&

677 Blackburn, D. (2018). The Walking Dead: Status Report, Data Workflow and Best Practices of 678 the oVert Thematic Collections Network. Biodiv. Info. Sci. and Stand. 2, e26078

679 Zug, G. (1978). Anuran locomotion-structure and function, 2: Jumping performance of 680 semiaquatic, terrestrial, and arboreal frogs. Smithson. Contrib. Zool. 276, 1-31 
Figure 1

Reconstructed DICE $\mu$ CT scan images of Phlyctimantis maculatus.

Created using N-Recon and CT-vox software. (A) Ventral, (B) lateral, and (C) dorsal view. Scale bar in white $1 \mathrm{~cm}$. 


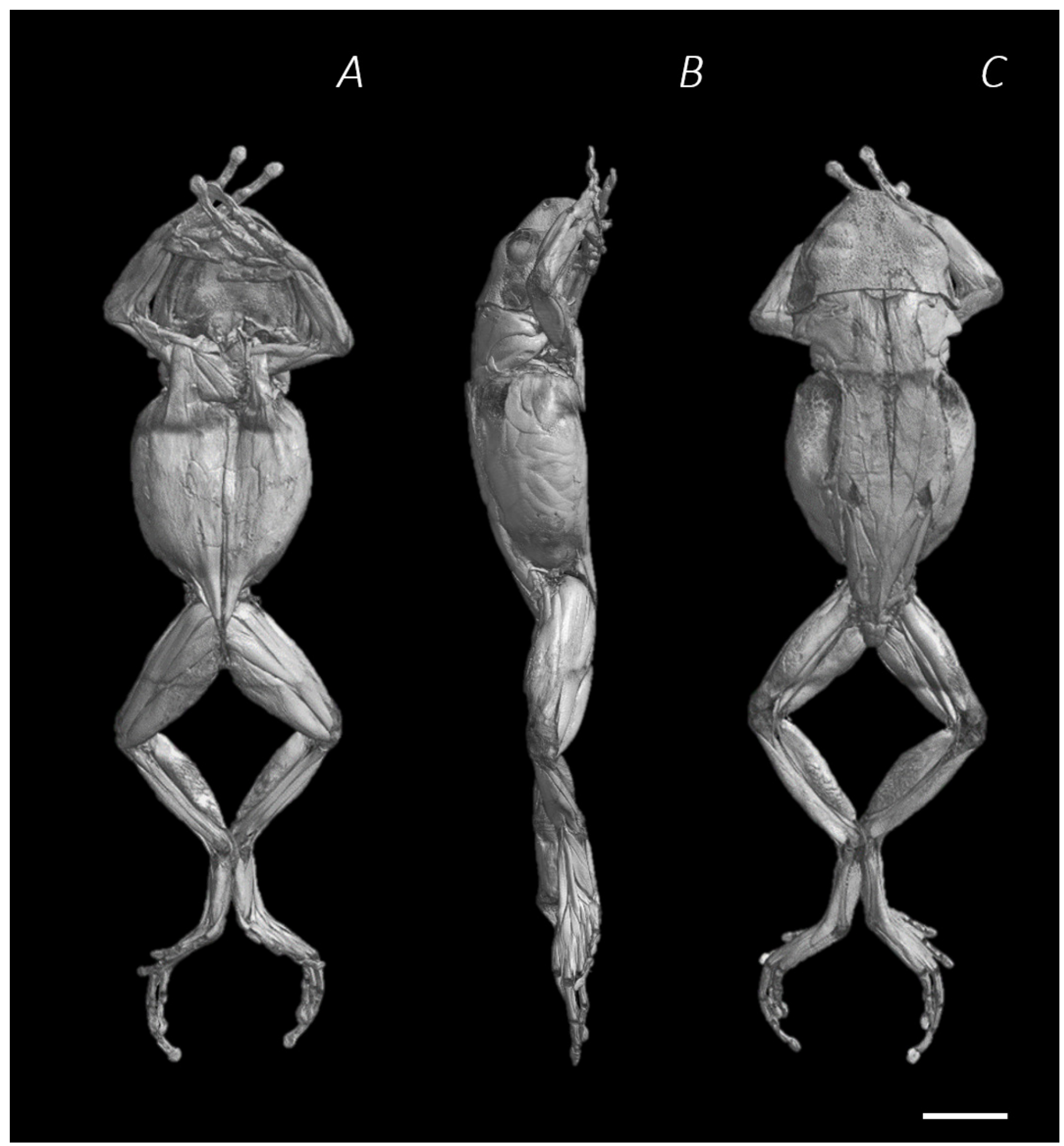




\section{Figure 2}

Reconstructed DICE $\mu$ CT scan images showing internal structure of the distal spine, pelvis, and hindlimb of Phlyctimantis maculatus.

(A) Posterior-oblique view of slices in the transverse, sagittal, and frontal planes, (B)

transverse section at the level of the hip joint, (C) sagittal section of the body and hindlimb, and (D) frontal view of the fully segmented model displaying all muscles and bones of the distal spine, pelvis, and hindlimbs. Scale bars in white, all $1 \mathrm{~cm}$.

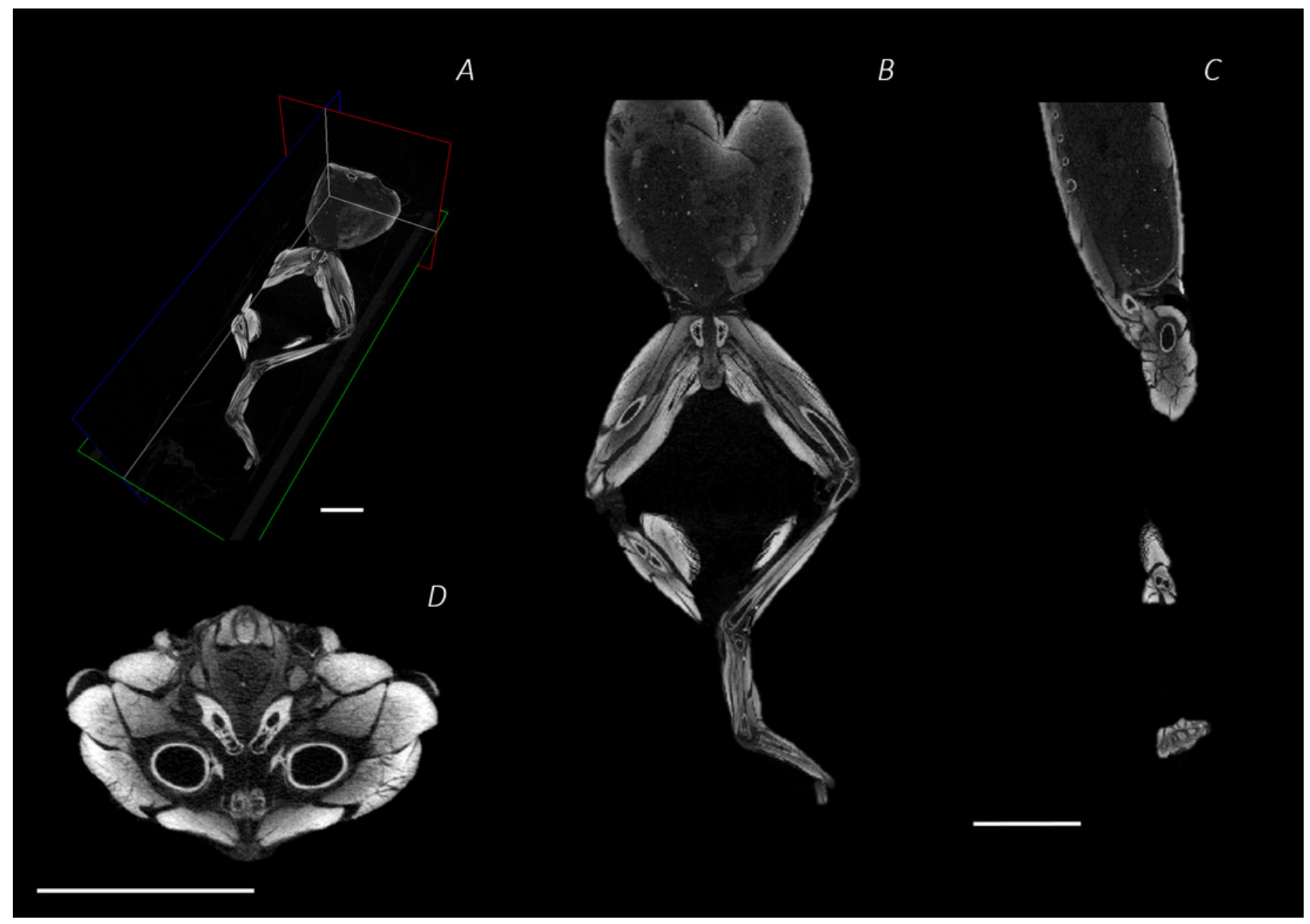




\section{Figure 3}

Superficial digital dissection of the distal spine, pelvis, and hindlimb of Phlyctimantis maculatus.

(A) Ventral, (B) lateral, and (C) dorsal view. See main text and Table 2 for muscle abbreviations. For the interactive 3D PDF, see Supplemental Information. Scale bar in black 1 $\mathrm{cm}$.
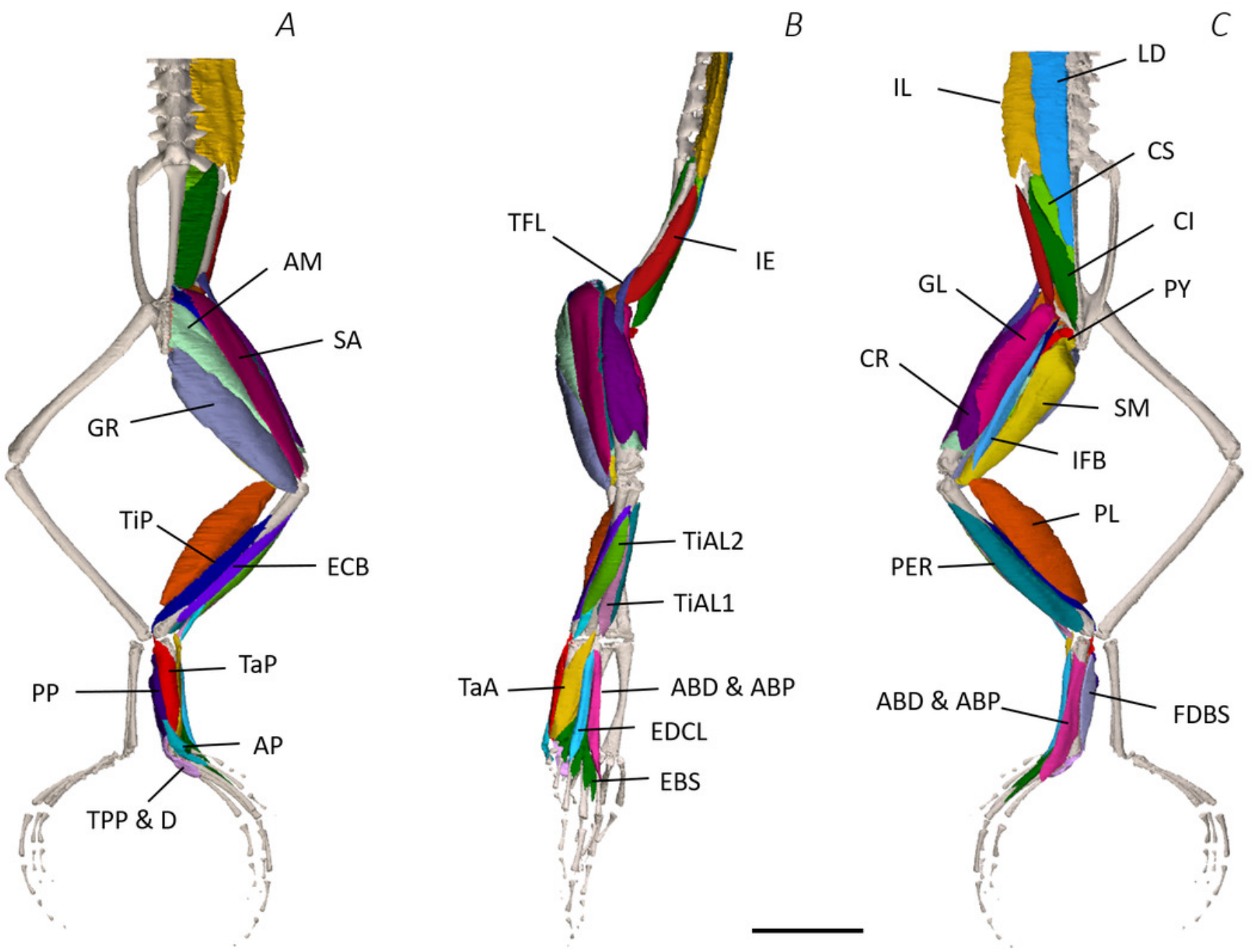
Figure 4

Medial digital dissection of the distal spine, pelvis, and hindlimb of Phlyctimantis maculatus.

(A) Ventral, (B) lateral, and (C) dorsal view. See main text and Table 2 for muscle abbreviations. For the interactive 3D PDF, see Supplemental Information. Scale bar in black 1 $\mathrm{cm}$.

$A$

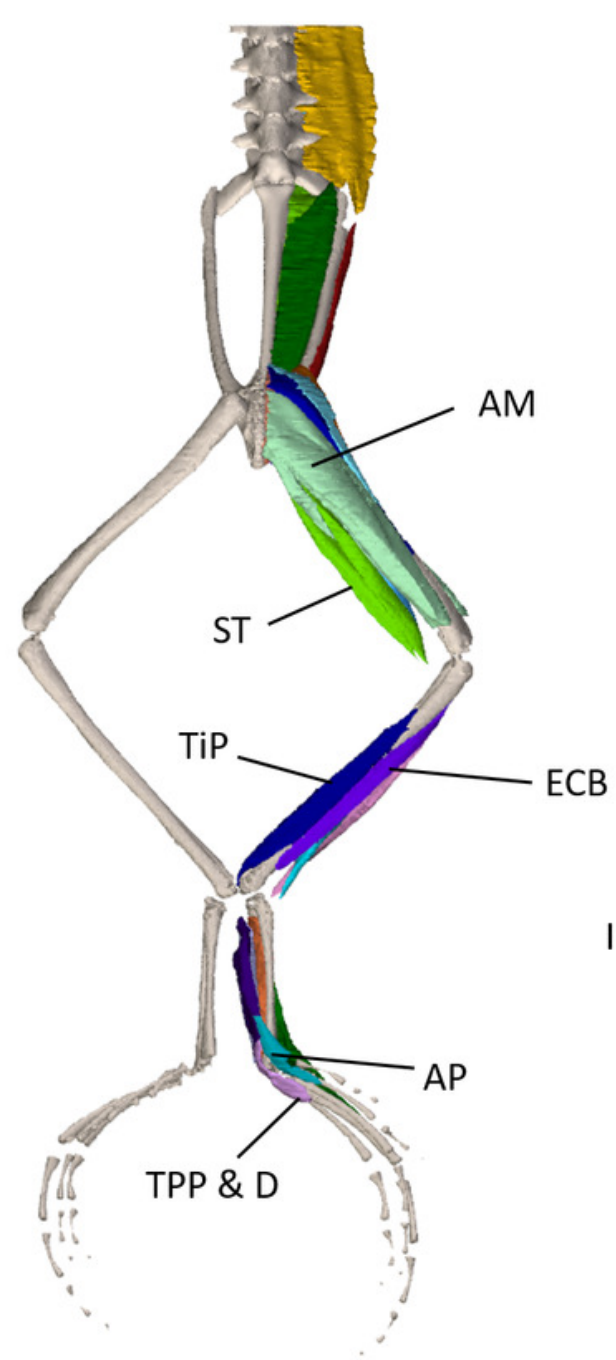

$B$

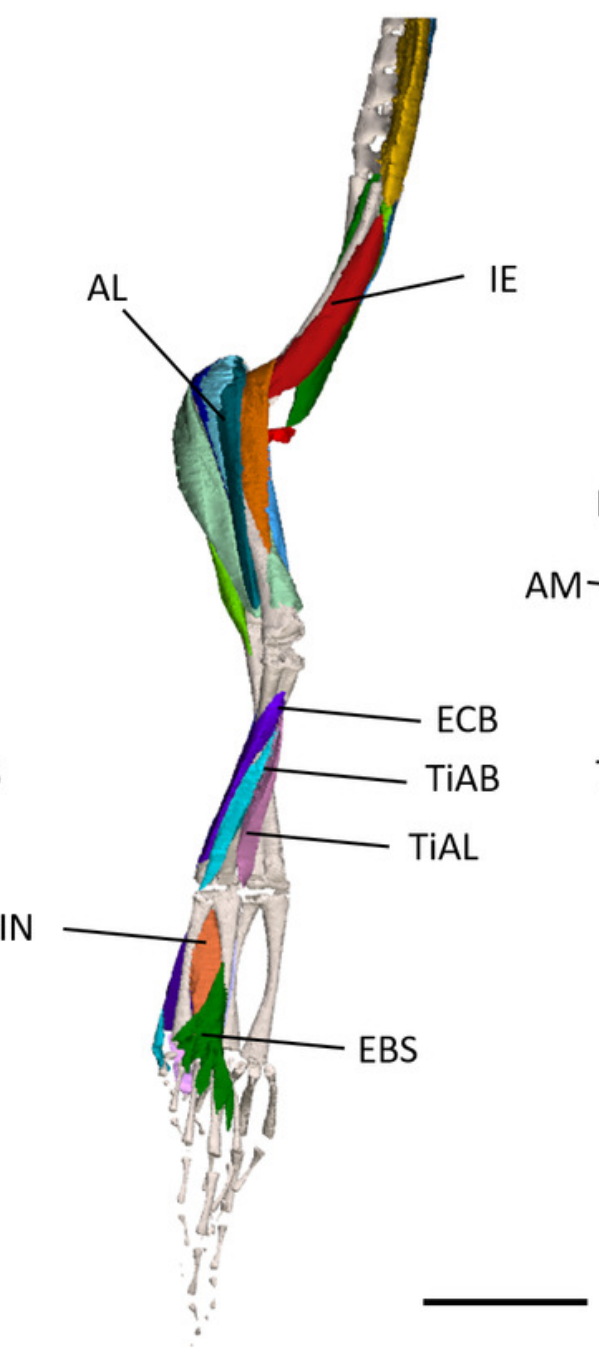

C

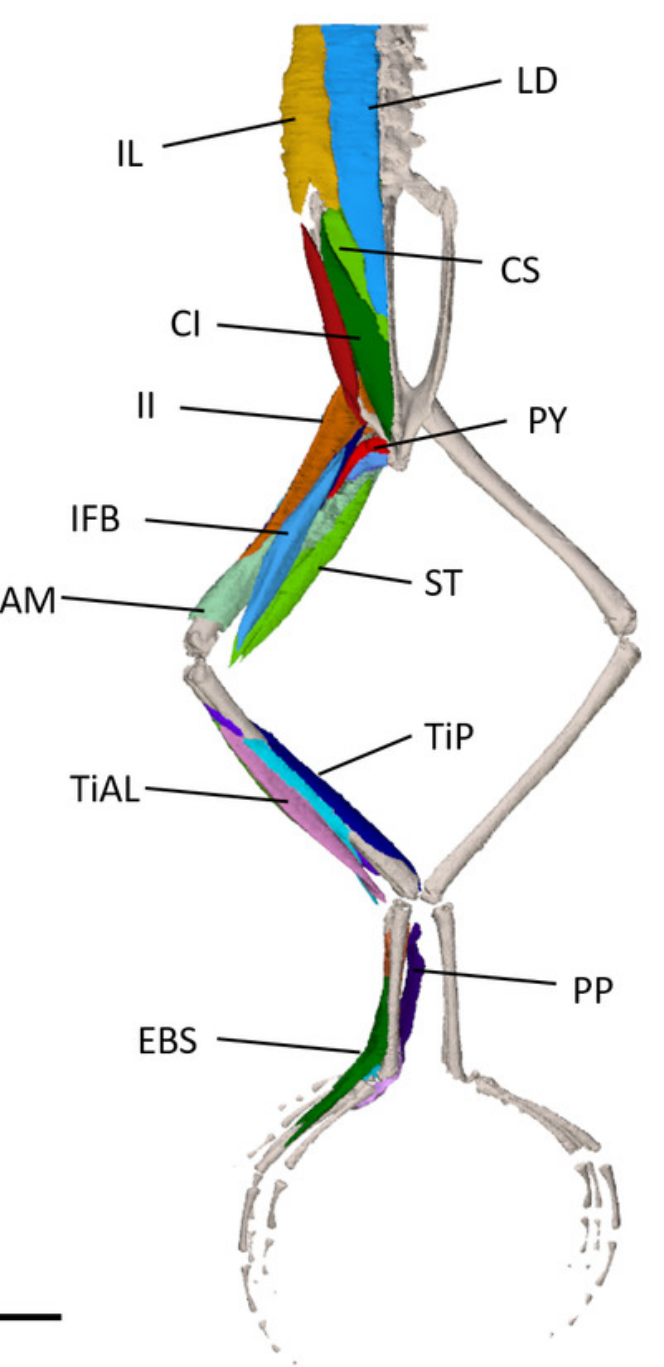


Figure 5

Deep digital dissection of the distal spine, pelvis, and hindlimb of Phlyctimantis maculatus.

(A) Ventral, (B) lateral, and (C) dorsal view. See main text and Table 2 for muscle abbreviations. For the interactive 3D PDF, see Supplemental Information. Scale bar in black 1 $\mathrm{cm}$.

$A$

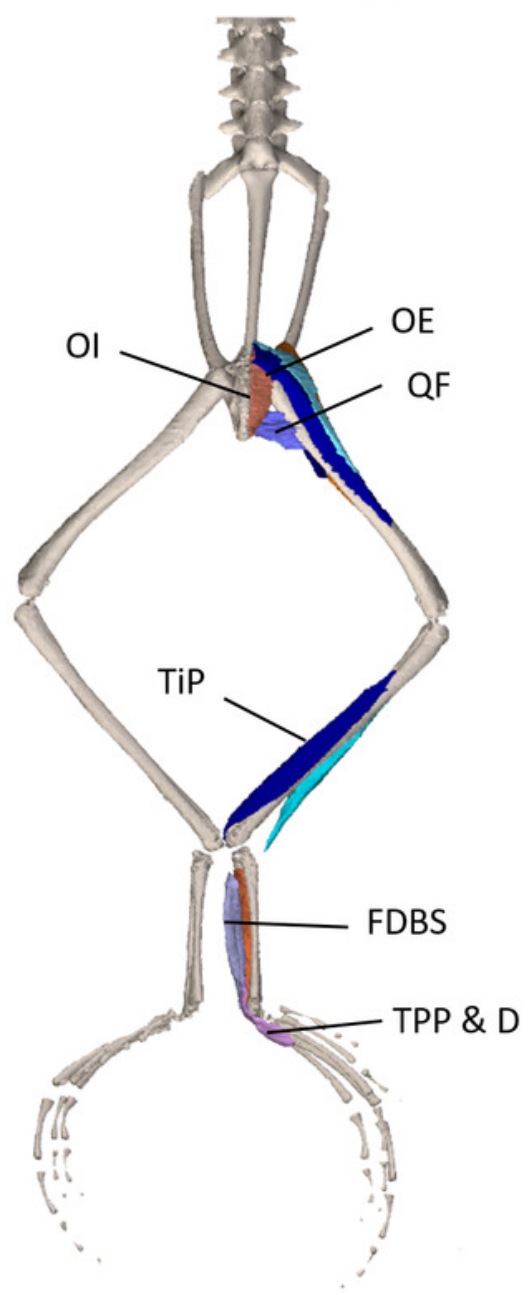

$B$

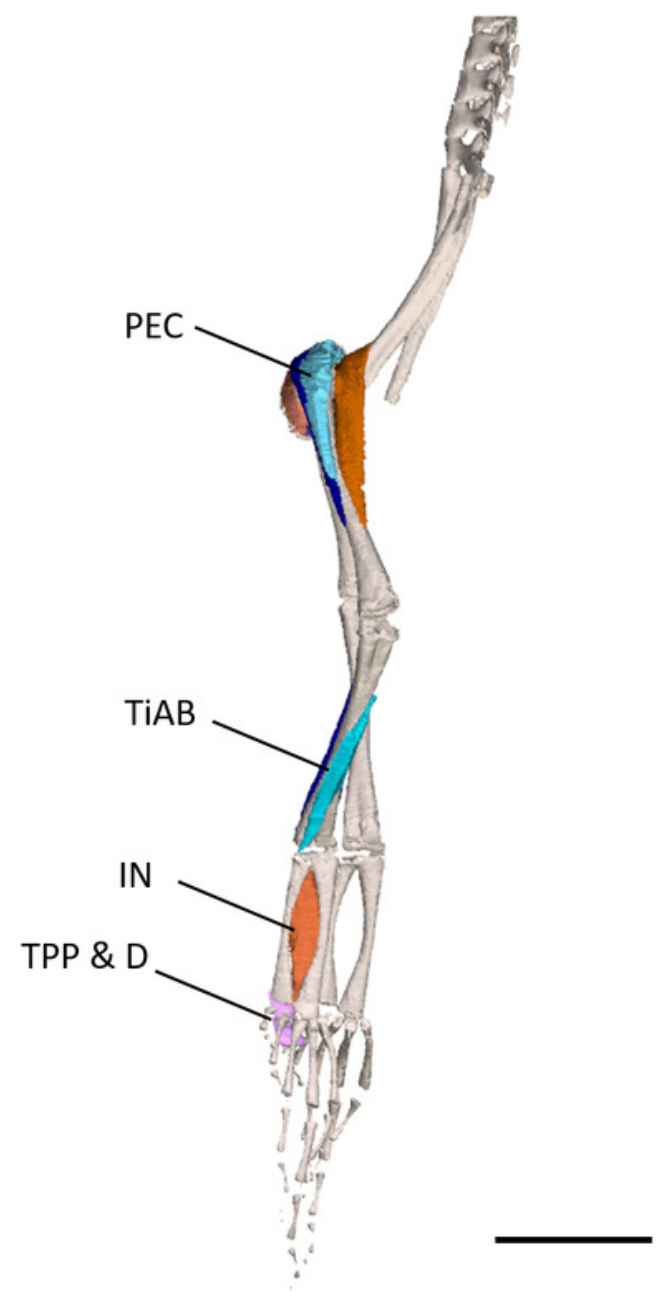

C

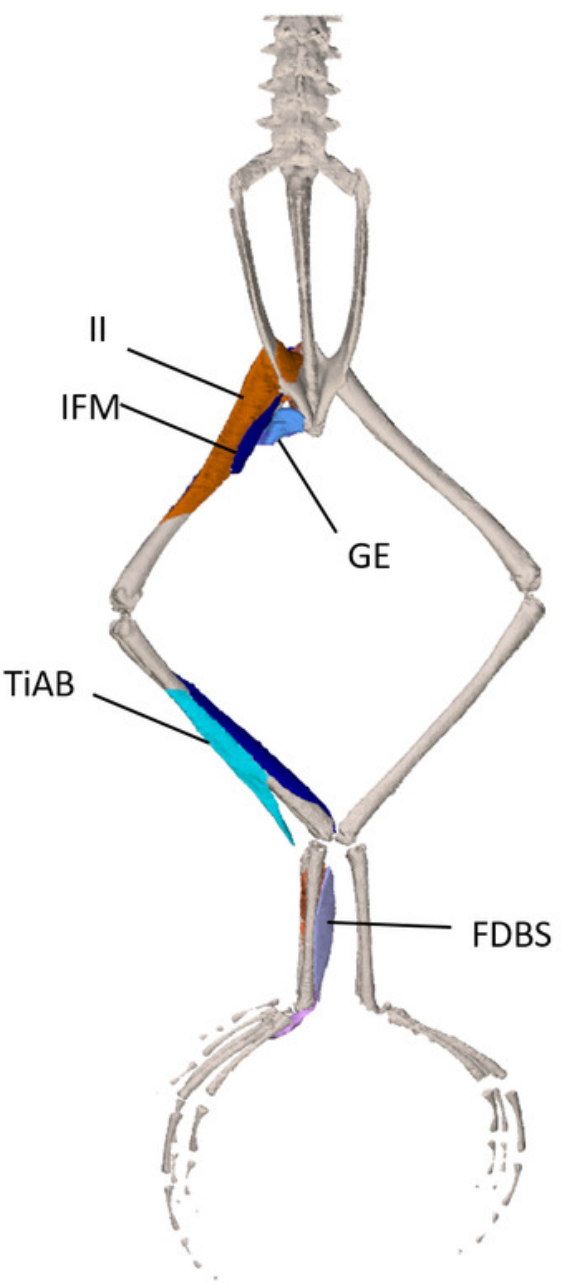


Figure 6

Skeletal digital dissection of the distal spine, pelvis, and hindlimb of Phlyctimantis maculatus.

(A) Ventral, (B) lateral, and (C) dorsal view. See Supplemental Information for the interactive 3D PDF. Scale bar in black $1 \mathrm{~cm}$.

A

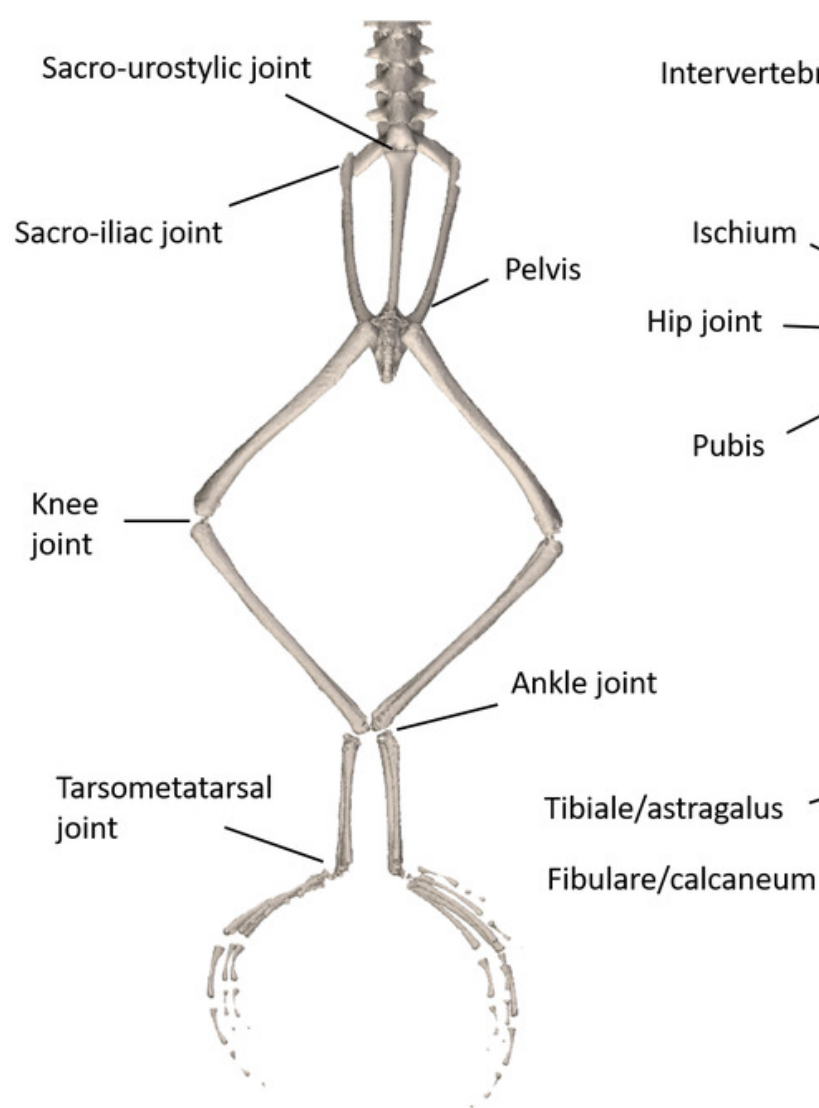

$B$

C

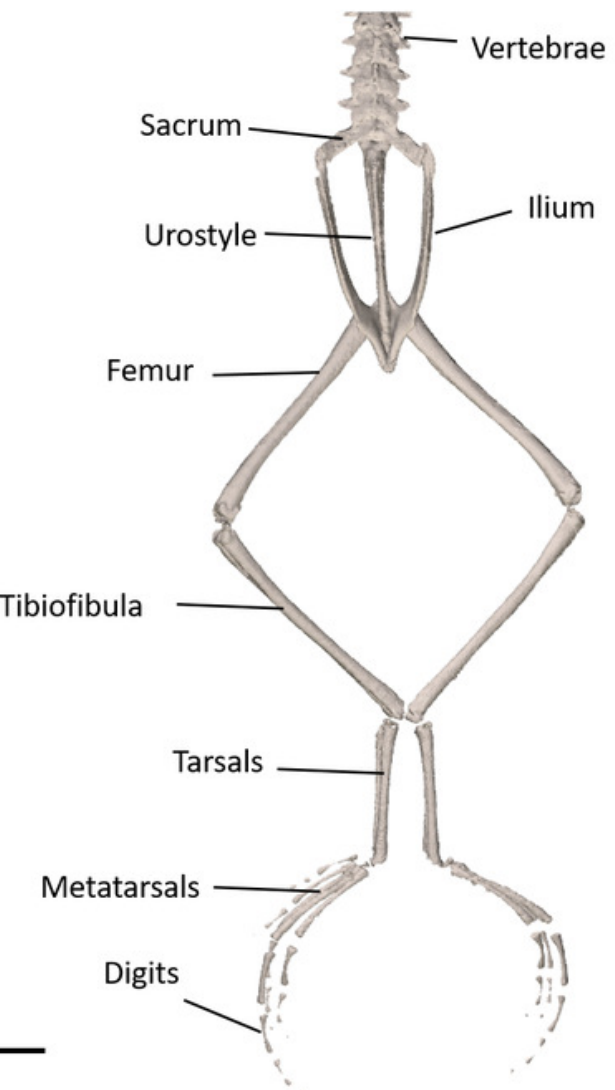




\section{Figure 7}

Traditional dissection photographs of the dorsal body (A), dorsal pelvis (B), dorsal (C) and ventral (D) left proximal hindlimb.

The red arrows indicate the dorsal fascia in (A), the knee aponeurosis in (C), and the small gracilis minor muscle in (D). The black dashed lines in (A) depict the external borders of the left IL muscle, note the posterior split. Scale bars are shown in white, all of which are $1 \mathrm{~cm}$. IL

- iliolumbaris, CS - coccygeosacralis, Cl - coccygeoiliacus, CR - cruralis, GL - gluteus maximus, SM - semimembranosus, PL - plantaris longus, PER - peroneus, AM - adductor magnus, SA - Sartorius, GR - gracilis. 


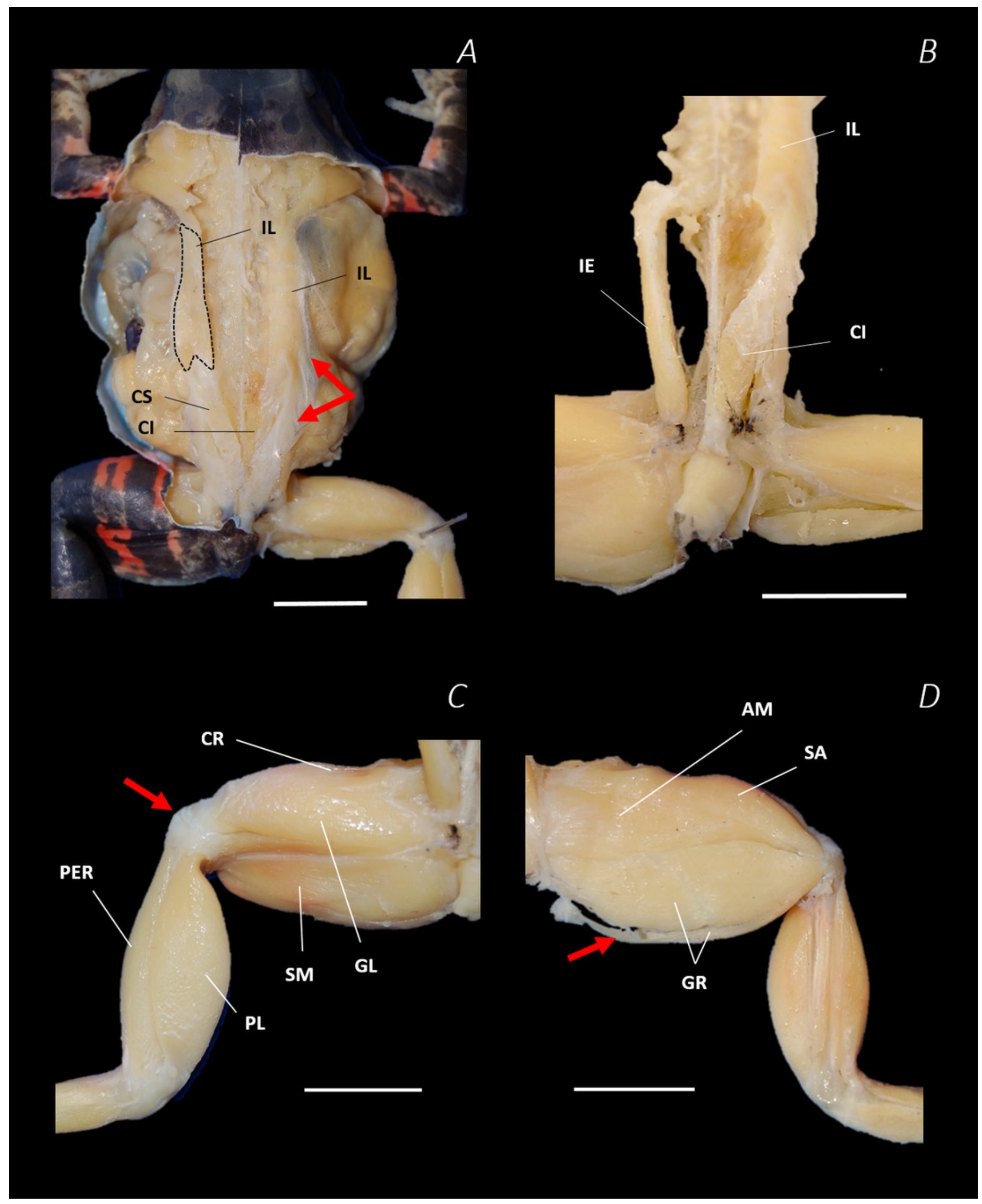




\section{Figure 8}

Isolated dissected longissimus dorsi (A), semimembranosus (C), and gracilis major (E) muscles alongside the reconstructed scan images of the external surface of longissimus dorsi and iliolumbaris (B), semimembranosus (D), and gracilis major (F).

Red arrows are used to show the presence of intersegmental and separating septa. Scale bars are shown in white, all of which are $1 \mathrm{~cm}$. 


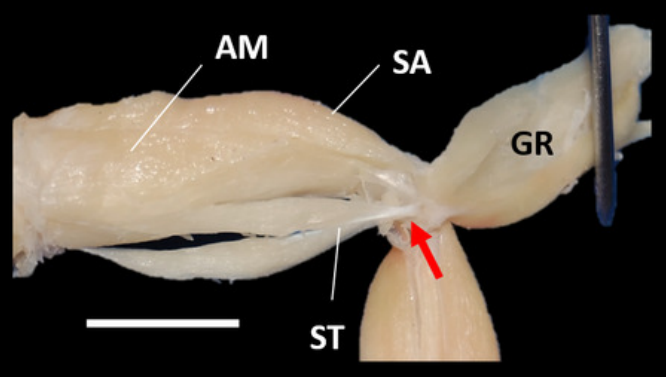

A

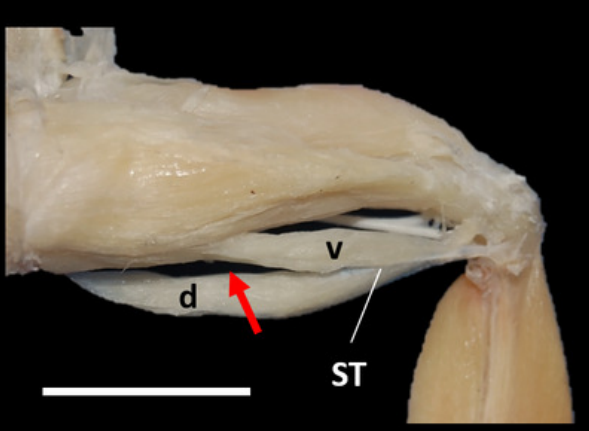

B

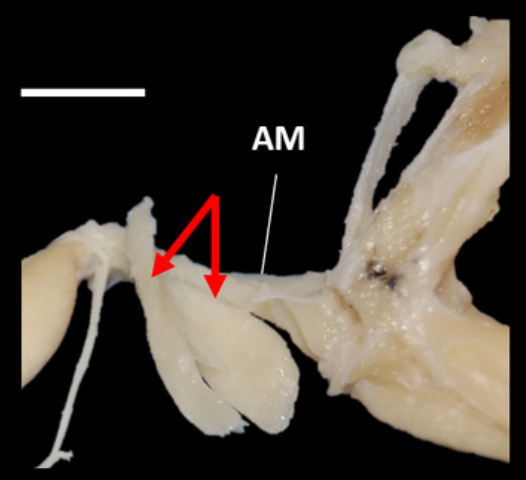

$D$

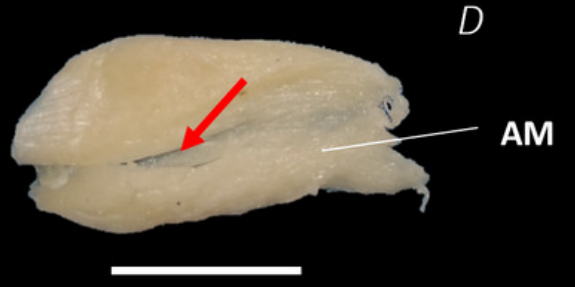

E

PEC
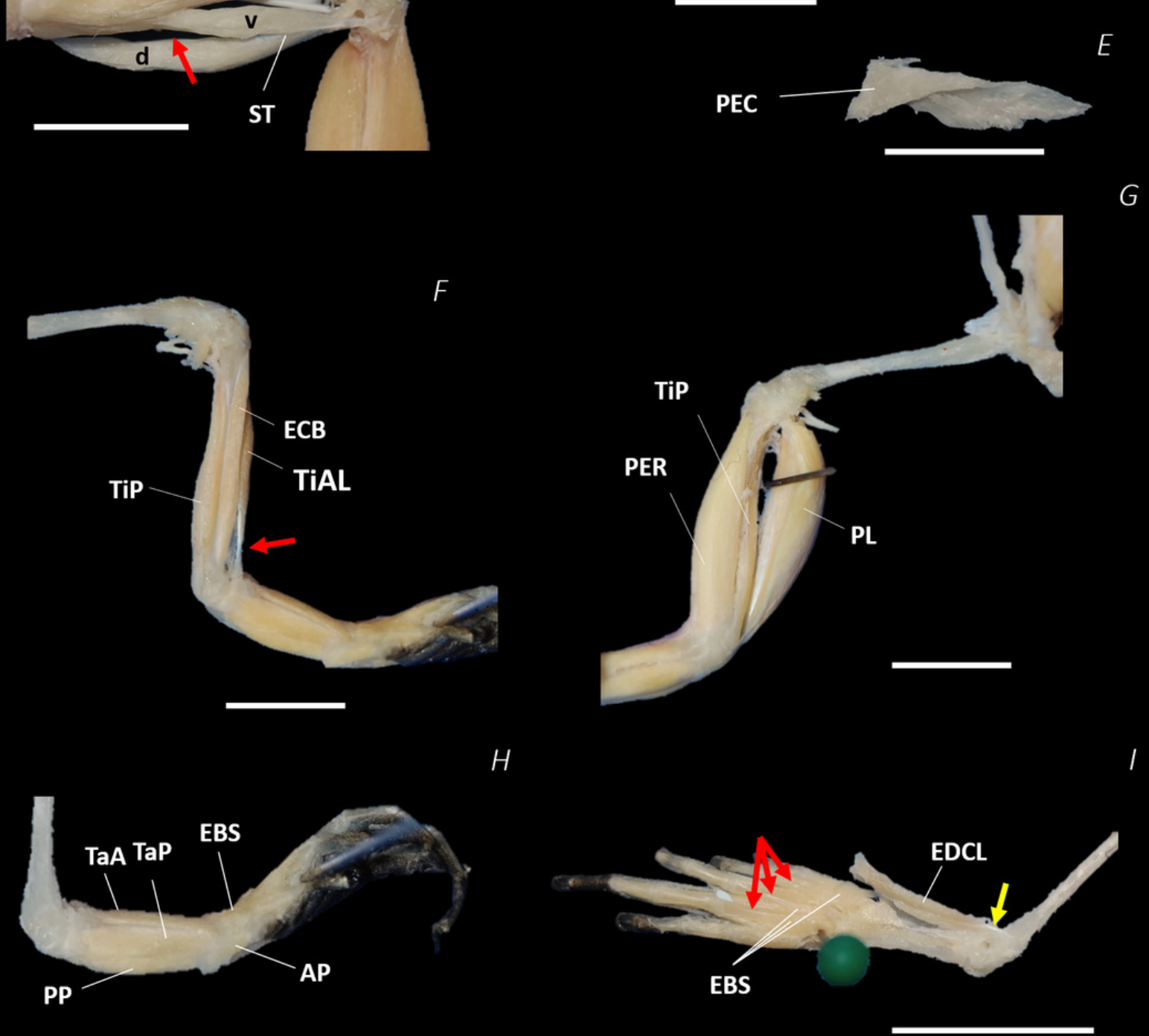

PeerJ reviewing PDF | (2018:12:33246:2:0:NEW 16 Apr 2019) 


\section{Figure 9}

Traditional dissection photographs of the left femur.

(A) Ventral view of ST tendinous insertion with GR reflected. (B) Ventral view of the dorsal (d) and ventral (v) heads of ST with GR removed entirely. (C) Posterior oblique dorsal view of the pelvis and left proximal hindlimb, note AM has been partially dissected and reflected in this image. (D) Isolated AM muscle. (E) Isolated PE muscle, (F) ventral view/medial side of the shank, (G) dorsal view/lateral side of the shank, (H) lateral view of the tarsals and foot. (I) Dorsal view of the tarsals and foot. The red arrows highlight the shared tendinous insertion of the dorsal and ventral heads of the ST muscle in (A), the insertion of STV into the AM muscle belly in (B), the two portions of the AM muscle in (C), the hiatus between the two AM muscle belly portions (through which the ventral tendon of semitendinosus passes) in (D), the tendinous insertion of TiAL (head 2) in (F), and the multiple tendons of the EBS muscle in (I). A yellow arrow highlights the tendinous origin of the EDCL in (I). Scale bars are shown in white, all of which are $1 \mathrm{~cm}$. AM - adductor magnus, SA - sartorius, GR - gracilis, ST semitendinosus, TiP - tibialis posticus, PE - pectineus, PER - peroneus, PL - plantaris longus, ECB - extensor cruris brevis, TiAL - tibialis anticus longus. TaA - tarsus anticus, TaP - tarsus posticus, EBS - extensor brevis superficialis, PP - plantaris profundus, AP - abductor prehallucis, EDCL - extensor digitorum communis longus. 


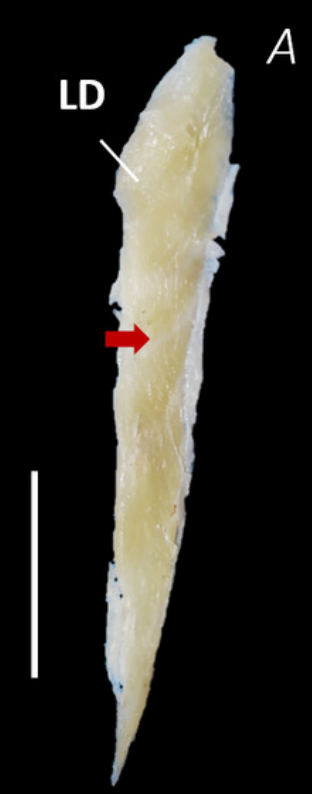

$B$
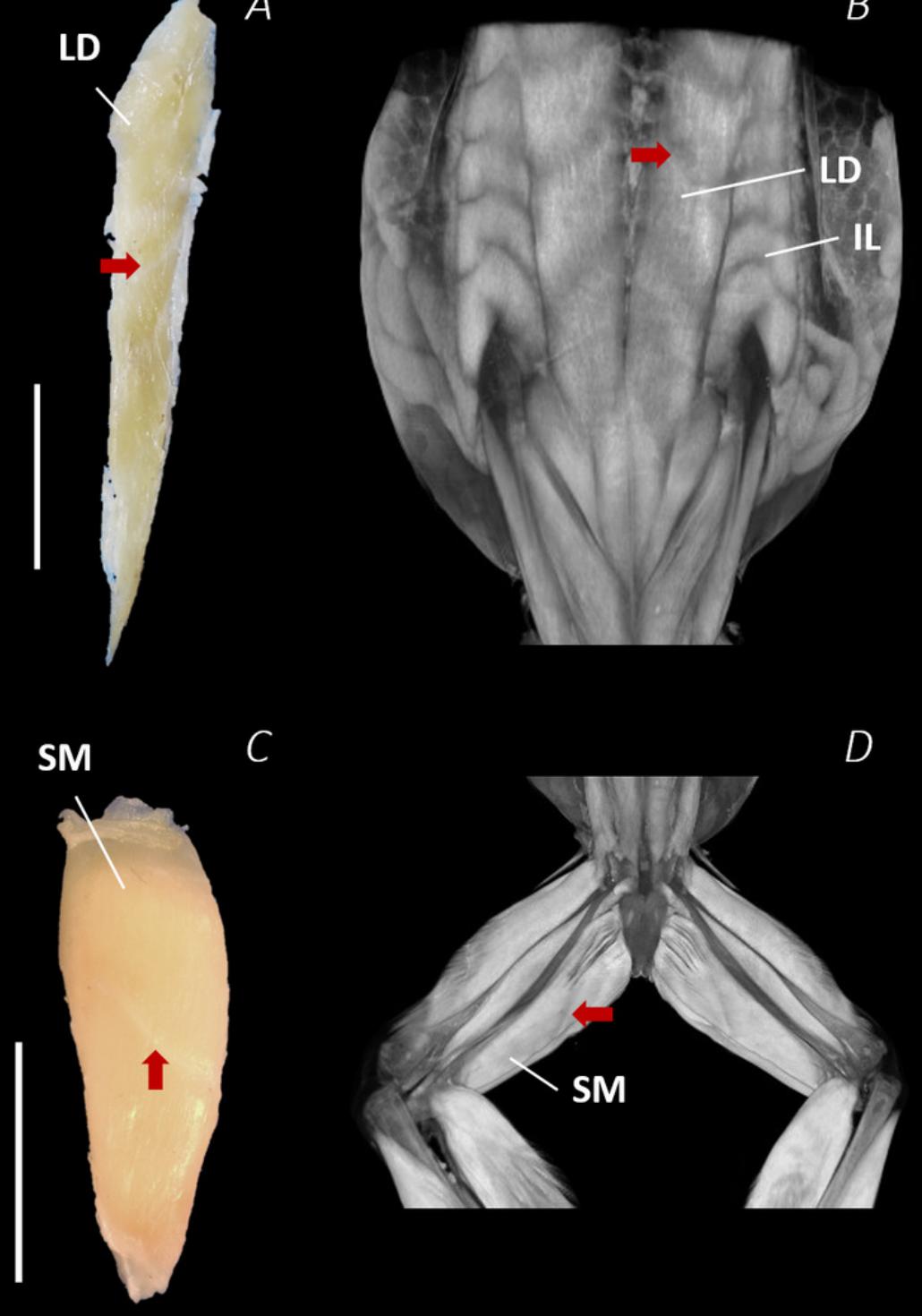

E
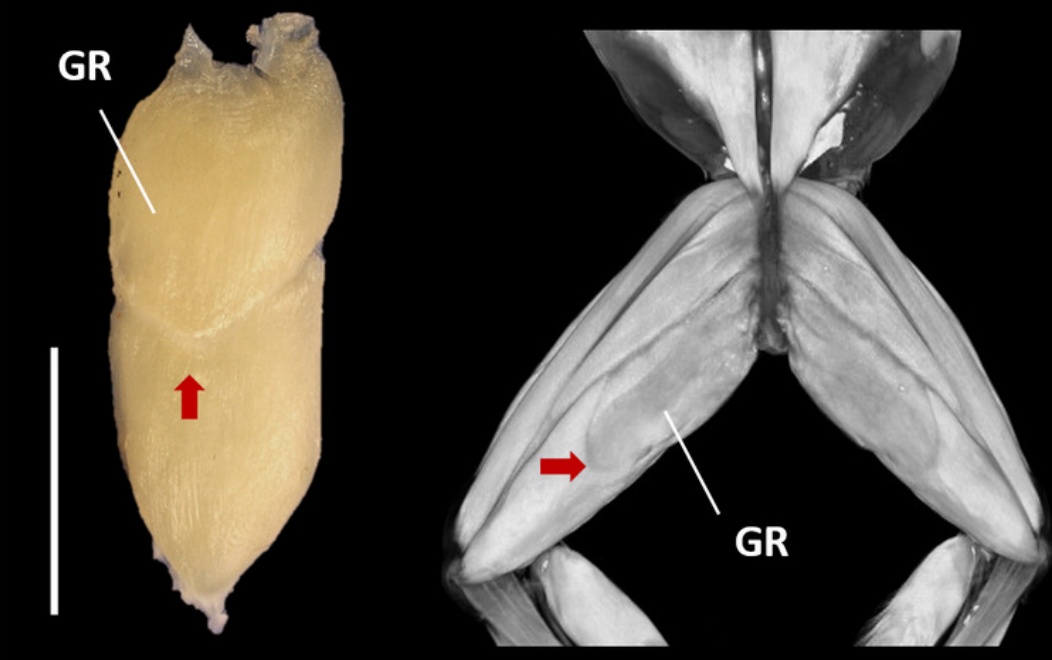

PeerJ reviewing PDF | (2018:12:33246:2:0:NEW 16 Apr 2019) 


\section{Figure 10}

Comparison between Emerson's characteristic Type IIA pelvic morphotype and traditional dissection data from Phlyctimantis maculatus.

(A) and (B) schematic diagrams adapted from Emerson (1982) and Emerson \& De Jongh (1980) show dorsal and posterior-oblique dorsal views, respectively. (C) Shaded traditional dissection photograph of the dorsal spine and pelvis of $P$. maculatus. LD - longissimus dorsi, blue shading, IL - iliolumbaris, yellow shading, CS - coccygeosacralis, light green shading, $\mathrm{Cl}$ - coccygeoiliacus, dark green shading, IE - iliacus externus, red shading. Articular ligament shaded purple.
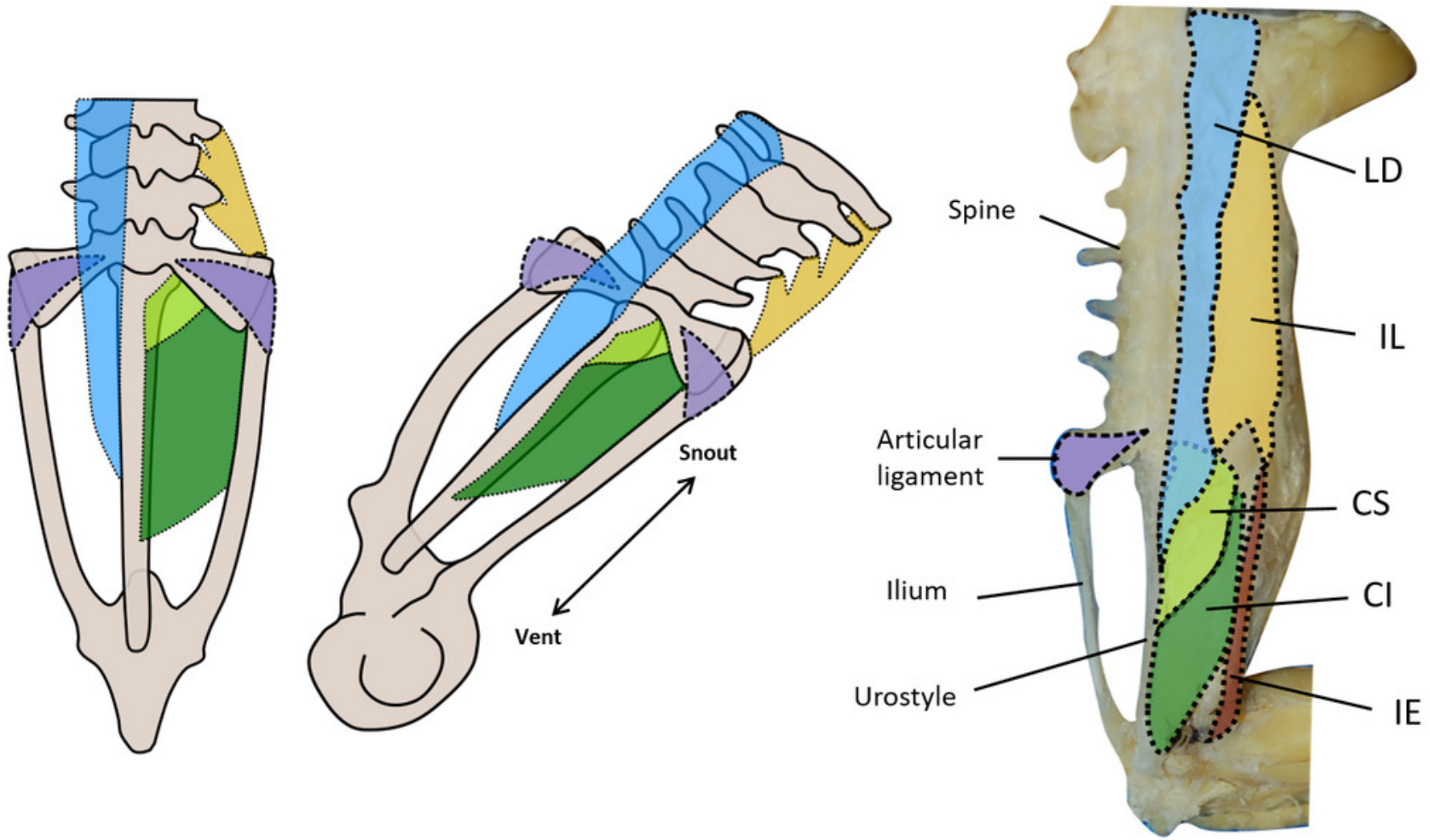


\section{Table $\mathbf{1}$ (on next page)}

Laboratory parameters for staining and scanning.

The staining regime used was continuous therefore cumulative stain duration refers to the number of days the specimen was exposed to the staining solution in total whereas stain duration details the duration of exposure to the stain in that particular test round. 


\begin{tabular}{|c|c|c|c|c|c|}
\hline Sample & $\begin{array}{c}\text { Stain } \\
\text { concentration }\end{array}$ & $\begin{array}{c}\text { Stain } \\
\text { duration }\end{array}$ & $\begin{array}{c}\text { Cumulative } \\
\text { stain } \\
\text { duration }\end{array}$ & Scan results & Recommendation \\
\hline $\begin{array}{l}\text { Whole, } \\
\text { Un-skinned }\end{array}$ & $7.5 \%$ & 3 days & 3 days & $\begin{array}{l}\text { No effect of } \\
\text { musculature }\end{array}$ & Skin specimen and stain further \\
\hline $\begin{array}{l}\text { Whole, } \\
\text { Skinned }\end{array}$ & $7.5 \%$ & 13.5 days & 16.5 days & $\begin{array}{l}\text { Stain not fully } \\
\text { perfused }\end{array}$ & $\begin{array}{l}\text { Stain further with increased } \\
\text { concentration }\end{array}$ \\
\hline $\begin{array}{l}\text { Whole, } \\
\text { Skinned }\end{array}$ & $20 \%$ & 7.5 days & 24 days & $\begin{array}{l}\text { Stain not fully } \\
\text { perfused }\end{array}$ & Stain further \\
\hline $\begin{array}{l}\text { Whole, } \\
\text { Skinned }\end{array}$ & $20 \%$ & 7.5 days & 31.5 days & $\begin{array}{l}\text { Stain not fully } \\
\text { perfused in the thigh }\end{array}$ & $\begin{array}{l}\text { Stain further, with some injection } \\
\text { of stain into thighs and body }\end{array}$ \\
\hline
\end{tabular}

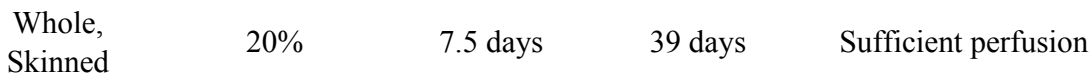

Final scan to be conducted using the following settings: $17.64 \mu \mathrm{m}$ resolution, $50 \mathrm{kV}, 362 \mu \mathrm{A}$, $1 \mathrm{~mm} \mathrm{Al} \mathrm{filter}$ 


\section{Table 2 (on next page)}

Summary table of gross anatomy of all of the axial, pelvic, and hindlimb muscles analysed from Phlyctimantis maculatus. 


\begin{tabular}{|c|c|c|c|}
\hline $\begin{array}{c}\text { Muscle } \\
\text { (Abbreviation) }\end{array}$ & Origin & Insertion & Notable features \\
\hline $\begin{array}{l}\text { Longissimus dorsi } \\
\text { (LD) }\end{array}$ & $\begin{array}{l}\text { Anterior spine and base of skull (atlas and } \\
\text { occipital bone) and vertebrae }\end{array}$ & Along the anterior half of the urostyle & \multirow{2}{*}{$\begin{array}{l}\text { Long muscles, consisting of multiple segments, unified by } \\
\text { thin septa, which each originate from individual vertebrae } \\
\text { via fleshy connections. }\end{array}$} \\
\hline Iliolumbaris (IL) & Pre-sacral vertebrae & $\begin{array}{c}\text { Medially: sacral diapophysis } \\
\text { Laterally: sacroiliac joint and anterior iliac shaft }\end{array}$ & \\
\hline $\begin{array}{l}\text { Coccygeosacralis } \\
\text { (CS) }\end{array}$ & $\begin{array}{l}\text { Dorsal sacral diapophysis and proximal } \\
\text { urostyle }\end{array}$ & Urostyle & \multirow{2}{*}{$\begin{array}{l}\text { Roughly triangular in shape and fill the space between the } \\
\text { ilia and urostyle. Fleshy attachments. }\end{array}$} \\
\hline $\begin{array}{l}\text { Coccygeoiliacus } \\
\text { (CI) }\end{array}$ & $\begin{array}{l}\text { Sacral diapophysis and medial, anterior iliac } \\
\text { shaft }\end{array}$ & Medial surface of urostyle & \\
\hline Pyriformis (PY) & Posterior urostyle & Proximal femur & Present as a small slip of muscle. \\
\hline $\begin{array}{l}\text { Iliacus externus } \\
\text { (IE) }\end{array}$ & Lateral surface of iliac shaft & Proximal femur & $\begin{array}{l}\text { Narrow and cylindrical muscle with large fleshy origin and } \\
\text { tendinous insertion. }\end{array}$ \\
\hline Iliacus internus (II) & Medial surface of the ilium & Proximal femur & $\begin{array}{l}\text { Wraps ventrally around the ilia from origin to insertion. } \\
\text { Fleshy attachments. }\end{array}$ \\
\hline $\begin{array}{l}\text { Tensor Fascia Latte } \\
\text { (TFL) }\end{array}$ & Lateral Ilium & Cruralis muscle & Small slip of muscle with soft tissue insertion. \\
\hline $\begin{array}{l}\text { Gluteus maximus } \\
\qquad(\mathrm{GL})\end{array}$ & Ilium & Cruralis muscle/Knee aponeurosis & Soft tissue insertion. \\
\hline Cruralis (CR) & Ventral border of the ilium & $\begin{array}{l}\text { Knee aponeurosis of anterior surface of the knee } \\
\text { joint }\end{array}$ & Large muscle forming the knee aponeurosis distally. \\
\hline $\begin{array}{l}\text { Gracilis minor (GR } \\
\text { major) }\end{array}$ & \multirow{2}{*}{ Ischium } & \multirow{2}{*}{ Knee aponeurosis medially } & $\begin{array}{l}\text { Large fleshy muscle separated roughly in half be a } \\
\text { connective tissue septum. }\end{array}$ \\
\hline $\begin{array}{l}\text { Gracilis major }(\mathrm{GR} \\
\text { minor) }\end{array}$ & & & $\begin{array}{l}\text { Small thin belly that runs along the lateral side of the major } \\
\text { belly. }\end{array}$ \\
\hline $\begin{array}{l}\text { Semimembranosus } \\
\text { (SM) }\end{array}$ & Dorsal rim of ischium and ilium & Knee aponeurosis laterally and ventrally & $\begin{array}{l}\text { Large fleshy muscle separated roughly in half be a } \\
\text { connective tissue septum. }\end{array}$ \\
\hline Iliofibularis (IFB) & Ilium & Knee aponeurosis laterally & Narrow and cylindrical. \\
\hline Iliofemoralis (IFM) & Ventral border of the ilium & $\begin{array}{l}\text { Femur approximately mid-shaft proximo- } \\
\text { distally }\end{array}$ & Narrow and cylindrical. \\
\hline
\end{tabular}




\begin{tabular}{|c|c|c|c|}
\hline Sartorius (SA) & Ventral border of the ischium & Knee aponeurosis medially & Long strap muscle. \\
\hline $\begin{array}{l}\text { Adductor longus } \\
\qquad(\mathrm{AL})\end{array}$ & Ventral border of the ischium & Knee aponeurosis medially & Present as a long strap muscle. \\
\hline $\begin{array}{l}\text { Semitendinosus } \\
\text { dorsal head (STd) }\end{array}$ & Posterior ventral border of the ischium & \multirow{2}{*}{ Tibiofibula ventrally } & \multirow{2}{*}{$\begin{array}{l}\text { Two heads with tendinous origins that share a common } \\
\text { tendinous insertion. The ventral head passes through the } \\
\text { adductor magnus muscle belly. }\end{array}$} \\
\hline $\begin{array}{c}\text { Semitendinosus } \\
\text { ventral head (STv) }\end{array}$ & Posterior dorsal border of the ischium & & \\
\hline Pectineus (PE) & Ventral border of the ischium & $\begin{array}{l}\text { Femur approximately mid-shaft proximo- } \\
\text { distally }\end{array}$ & $\begin{array}{l}\text { Twisted muscle belly. Shares fleshy origin with and inserts } \\
\text { slightly proximal to obturator externus. }\end{array}$ \\
\hline $\begin{array}{l}\text { Obturator externus } \\
\qquad(\mathrm{OE})\end{array}$ & Ventral border of the ischium & $\begin{array}{l}\text { Femur approximately mid-shaft proximo- } \\
\text { distally }\end{array}$ & Shares fleshy origin with pectineus. \\
\hline $\begin{array}{l}\text { Adductor magnus } \\
\qquad(\mathrm{AM})\end{array}$ & Ventral border of the ischium & Femur distal shaft & $\begin{array}{l}\text { Large muscle with two sections, perforated by the ventral } \\
\text { head of the semitendinosus. Wraps around the femur almost } \\
\text { entirely enveloping the distal third of it. }\end{array}$ \\
\hline $\begin{array}{l}\text { Quadratus femoris } \\
\qquad(\mathrm{QF})\end{array}$ & Ischium & Proximal femur & Interacts closely with gemellus to present as single mass. \\
\hline $\begin{array}{l}\text { Obturator internus } \\
\qquad(\mathrm{OI})\end{array}$ & Entire pelvic rim & Proximal femur & Forms a fleshy ring around the hip joint. \\
\hline Gemellus (GE) & Ischium & Proximal femur & $\begin{array}{l}\text { Interacts closely with quadratus femoris to present as single } \\
\text { mass. }\end{array}$ \\
\hline $\begin{array}{l}\text { Plantaris longus } \\
\qquad(\mathrm{PL})\end{array}$ & Knee aponeurosis posteriorly & Plantar aponeurosis via long tendon & $\begin{array}{l}\text { Large pennate biarticular muscle with a long tendon that } \\
\text { merges with the plantar aponeurosis. }\end{array}$ \\
\hline $\begin{array}{l}\text { Tibialis posticus } \\
\qquad(\mathrm{TiP})\end{array}$ & Posterior surface of tibiofibula & Astralagus & Distally tapered muscle belly with a tendinous insertion. \\
\hline
\end{tabular}

Tibialis anticus

longus head 1

(TiAL1)

Tibialis anticus

longus head 2

(TiAL2)
Lateral border of the proximal calcaneum

Knee aponeurosis laterally

Medial border of proximal astralagus
Two distinct heads that are roughly equal in size, sharing a tendinous origin with separate tendinous insertions. 


\begin{tabular}{|c|c|c|c|}
\hline Peroneus (PER) & Knee aponeurosis laterally & Distal tibiofibula laterally & Cylindrical muscle covering lateral surface of tibiofibula. \\
\hline $\begin{array}{l}\text { Extensor cruris } \\
\text { brevis (ECB) }\end{array}$ & Knee aponeurosis & Anterior medial surface of the tibiofibula & Narrow cylindrical muscle. \\
\hline $\begin{array}{l}\text { Tibialis anticus } \\
\text { brevis (TiAB) }\end{array}$ & Anterior surface of tibiofibula & Medial surface of the proximal astralagus & Large fleshy origin covering tibiofibula laterally. \\
\hline $\begin{array}{l}\text { Plantaris profundus } \\
\qquad(\mathrm{PP})\end{array}$ & Calcaneal ligament & Plantar aponeurosis & Separate to flexor digitorum brevis superficialis. \\
\hline $\begin{array}{l}\text { Tarsalis posticus } \\
\qquad(\mathrm{TaP})\end{array}$ & Calcaneal ligament & Distal astralagus & Roughly rectangular shaped muscle. \\
\hline $\begin{array}{l}\text { Flexor digitorum } \\
\text { brevis superficialis } \\
\text { (FDBS) }\end{array}$ & Calcaneal ligament & Penetrates into plantar aponeurosis & Thin muscle belly. \\
\hline $\begin{array}{c}\text { Transversus } \\
\text { plantae proximalis } \\
\text { and distalis (TPP } \\
\text { and D) }\end{array}$ & Distal calcaneum and plantar cartilage & Plantar aponeurosis & Unified as one muscle but extremely fragile. \\
\hline Intertarsalis (IN) & $\begin{array}{l}\text { Lateral margin of the astralagus and medial } \\
\text { margin of the calcaneum }\end{array}$ & Tendinous insertion at distal union of tarsals & $\begin{array}{l}\text { Pennate muscle filling the gap between the elongate tarsal } \\
\text { bones. }\end{array}$ \\
\hline $\begin{array}{l}\text { Extensor digitorum } \\
\text { communis longus } \\
(\text { EDCL })\end{array}$ & Lateral side of distal tibiofibula & Third digit of foot & $\begin{array}{l}\text { Long narrow muscle with tendinous origin in common with } \\
\text { tarsalis anticus. }\end{array}$ \\
\hline $\begin{array}{c}\text { Extensor brevis } \\
\text { superficialis (EBS) }\end{array}$ & Dorsal and medial surface of the calcaneum & Tendinous insertions into the digits of the foot & $\begin{array}{l}\text { Multiple bellies with tendinous insertions sharing a common } \\
\text { fleshy origin. }\end{array}$ \\
\hline $\begin{array}{l}\text { Adductor brevis } \\
\text { dorsalis and } \\
\text { plantaris (ABD and } \\
\text { P) }\end{array}$ & Medial surface of calcaneum & Fifth metatarsal and digit & Challenging to separate the two muscle bellies. \\
\hline $\begin{array}{l}\text { Tarsalis anticus } \\
\qquad(\mathrm{TaA})\end{array}$ & Lateral side of distal tibiofibula & Dorsal surface of the astralagus & $\begin{array}{l}\text { Roughly rectangular shaped with a tendinous origin in } \\
\text { common with extensor digitorum communis longus. }\end{array}$ \\
\hline $\begin{array}{c}\text { Adductor } \\
\text { prehallucis (AP) }\end{array}$ & Edge of plantar aponeurosis & Pre-hallux & Small superficial slip of muscle. \\
\hline
\end{tabular}

1 